\title{
Actin Cytoskeleton Regulation by the Yeast NADPH Oxidase Yno1p Impacts Processes Controlled by MAPK Pathways
}

\author{
Manuela Weber ${ }^{1}$, Sukanya Basu ${ }^{2}$, Beatriz González ${ }^{2}$, Gregor P. Greslehner ${ }^{1} \oplus$, Stefanie Singer ${ }^{1}$, \\ Danusa Haskova $^{3}$, Jiri Hasek ${ }^{3}{ }^{(}$, Michael Breitenbach ${ }^{1}$, Campbell W.Gourlay ${ }^{4}\left(\mathbb{D}\right.$, Paul J. Cullen ${ }^{2, *(1)}$ and \\ Mark Rinnerthaler ${ }^{1, *(1)}$
}

1 Department of Biosciences, University of Salzburg, 5020 Salzburg, Austria; manuela.weber@stud.sbg.ac.at (M.W.); gregor.greslehner@univie.ac.at (G.P.G.); Steffi_singer_14@gmx.de (S.S.); michael.breitenbach@sbg.ac.at (M.B.)

2 Department of Biological Sciences, State University of New York at Buffalo, Buffalo, NY 14260-1300, USA; basus@buffalo.edu (S.B.); beatrizg@buffalo.edu (B.G.)

3 Laboratory of Cell Reproduction, Institute of Microbiology of the Czech Academy of Sciences, Videnska 1083, 14220 Prague 4, Czech Republic; danusa.haskova@biomed.cas.cz (D.H.); hasek@biomed.cas.cz (J.H.)

4 Kent Fungal Group, School of Biosciences, University of Kent, Kent CT2 9HY, UK; C.W.Gourlay@kent.ac.uk

* Correspondence: pjcullen@buffalo.edu (P.J.C.); mark.rinnerthaler@sbg.ac.at (M.R.)

check for updates

Citation: Weber, M.; Basu, S.; González, B.; Greslehner, G.P.; Singer, S.; Haskova, D.; Hasek, J.; Breitenbach, M.; W.Gourlay, C.; Cullen, P.J.; et al. Actin Cytoskeleton Regulation by the Yeast NADPH Oxidase Yno1p Impacts Processes Controlled by MAPK Pathways. Antioxidants 2021, 10, 322. https:// doi.org/10.3390/antiox10020322

Academic Editors:

Rosario Ammendola and Fabio Cattaneo

Received: 31 December 2020

Accepted: 18 February 2021

Published: 22 February 2021

Publisher's Note: MDPI stays neutral with regard to jurisdictional claims in published maps and institutional affiliations.

Copyright: (c) 2021 by the authors. Licensee MDPI, Basel, Switzerland. This article is an open access article distributed under the terms and conditions of the Creative Commons Attribution (CC BY) license (https:// creativecommons.org/licenses/by/ $4.0 /)$.
Abstract: Reactive oxygen species (ROS) that exceed the antioxidative capacity of the cell can be harmful and are termed oxidative stress. Increasing evidence suggests that ROS are not exclusively detrimental, but can fulfill important signaling functions. Recently, we have been able to demonstrate that a NADPH oxidase-like enzyme (termed Ynolp) exists in the single-celled organism Saccharomyces cerevisiae. This enzyme resides in the peripheral and perinuclear endoplasmic reticulum and functions in close proximity to the plasma membrane. Its product, hydrogen peroxide, which is also produced by the action of the superoxide dismutase, Sod1p, influences signaling of key regulatory proteins Ras2 $p$ and Yck1p/2p. In the present work, we demonstrate that Yno1p-derived $\mathrm{H}_{2} \mathrm{O}_{2}$ regulates outputs controlled by three MAP kinase pathways that can share components: the filamentous growth (filamentous growth MAPK (fMAPK)), pheromone response, and osmotic stress response (hyperosmolarity glycerol response, HOG) pathways. A key structural component and regulator in this process is the actin cytoskeleton. The nucleation and stabilization of actin are regulated by Yno1p. Cells lacking YNO1 showed reduced invasive growth, which could be reversed by stimulation of actin nucleation. Additionally, under osmotic stress, the vacuoles of a $\Delta y n o 1$ strain show an enhanced fragmentation. During pheromone response induced by the addition of alpha-factor, Yno1p is responsible for a burst of ROS. Collectively, these results broaden the roles of ROS to encompass microbial differentiation responses and stress responses controlled by MAPK pathways.

Keywords: ROS; MAP kinase pathway; actin; osmotic stress; filamentous growth; invasive growth; pseudohyphal growth; pheromone response; apoptosis

\section{Introduction}

NADPH oxidases are a class of enzymes that consist of six to seven transmembrane helices that coordinate two non-identical heme $b$ molecules via four highly conserved histidines. These proteins catalyze the transfer of electrons from NADPH to FADH, from FADH to the two heme $b$ groups and finally to $\mathrm{O}_{2}$ leading to the production of superoxide $\left(\mathrm{O}_{2}{ }^{-}\right)$[1]. The first NADPH oxidase was identified in humans because a lack of this enzyme's activity is the main driver of chronic granulomatous disease that leads to death during early childhood, which has been attributed to a multitude of infections. Leukocytes of these patients have a defect in the enzyme Nox2 and, thus, lack the ability to perform a respiratory burst that is an important parameter of the innate immune defense [2-4]. Therefore, it was assumed for some time that NADPH oxidases are restricted 
to multicellular organisms. Contradicting this assumption, we were able to demonstrate that a NADPH oxidase-like enzyme (Ynolp) exists in the single-celled yeast Saccharomyces cerevisiae [5]. Confirming our result, homologous NADPH oxidases have been identified in other mono-cellular ascomycetes [6] and even bacteria [7].

In S. cerevisiae, the reactive oxygen species (ROS) produced by Yno1p primarily act as signaling molecules [5]. Although superoxide is directly produced, the main bioactive molecule is hydrogen peroxide [8]. The Yno1p-derived ROS are instantaneously dismutated to $\mathrm{H}_{2} \mathrm{O}_{2}$ by Sod1p [8]. In this way, a ROS producing and an antioxidative enzyme are in a strict dependence of each other to fulfil their function. Due to its localization in the peripheral endoplasmic reticulum (ER), Yno1p engages in signaling with proteins in the plasma membrane. The plasma membrane is an important mediator between the exterior and interior of the cell and is thus an important signaling platform for the cell. A multitude of signaling proteins function at the plasma membrane that include receptors, G-proteins, and protein and lipid kinases. A typical example are the yeast casein kinases, Yck1p and Yck2p, which are tethered to the cytoplasmic side of the plasma membrane by the lipid modification, palmitoylation [9]. Both kinases are involved in sensing extracellular glucose and control mediating its import, but are also involved in bud morphogenesis, pheromone signaling, cytokinesis and endocytosis [10-12]. It was shown that hydrogen peroxide derived from the Yno1p-Sod1p interaction stabilizes Yck1p in the plasma membrane. As a direct consequence, mitochondrial respiration is downregulated, and at the same time, glycolysis is promoted [8]. Another prominent example is the evolutionary highly conserved monomeric G-protein Ras2p [13]. Similar to Yck1p/Yck2p, Ras2p is involved in extracellular glucose sensing and can function in modulating mitochondrial respiration [14]. Defects in the mitochondrial electron transport chain can induce translocation of Ras2p from the plasma membrane to the mitochondria to mediate a burst of ROS production by Yno1p [15]. Localized ROS in proximity to the plasma membrane can modulate diverse processes ranging from apoptosis to F-actin polymerization [5]. The pathways that lead to the latter process are the focus of the present manuscript.

Many fungal species are capable of undergoing a nutrient-dependent growth response commonly referred to as filamentous growth. Filamentous occurs in many fungal species, and in fungal pathogens can be required for virulence [16]. In the major human fungal pathogen Candida albicans, the NADPH oxidase Fre8p resides in the plasma membrane, particularly at the growing tip of the cell. As in S. cerevisiae, the NADPH oxidase fulfills its function in concert with a superoxide dismutase. Unlike in baker's yeast, the resulting hydrogen peroxide acts in an extracellular manner. The resulting ROS burst is important for the transition from yeast to hyphal growth and differentiation to the infectious form of $C$. albicans. In a mouse model of candidiasis, $\Delta$ fre $8 / \Delta$ fre 8 strains showed significantly shortened hyphae [6].

In contrast to $C$. albicans, S. cerevisiae is not capable of forming true hyphae, but rather forms pseudohyphae, where cells fully separate by cytokinesis $[17,18]$. During pseudohyphal growth, cells become elongated due to an extended period of apical growth due to a delay in the cell cycle, which involves vesicle trafficking along a highly polarized actin-based cytoskeleton $[19,20]$. Cells also reorganize their polarity to grow outward from their ends at the distal poles [21]. In addition, cells remain attached to each other (and can attach to surfaces) due to contacts mediated by cell adhesion molecules. One tractable phenotype in S. cerevisiae and other fungal species is invasive growth, where filamentous cells penetrate into surfaces [22]. The route to filamentous growth in S. cerevisiae is complex and integrates signals from different pathways including the Ras2p-cAMP-protein kinase A (PKA) pathway [18,23-25], the Rim101 pathway [26], the Snf1p Nrg1p/Nrg2p pathway and a mitogen activated protein (MAP) kinase pathway commonly referred to as the filamentous growth or fMAPK (filamentous growth MAPK) pathway (Figure 1, [27]). The fMAPK pathway is regulated by a cell-surface glycoprotein, Msb2p, which controls the activity of the Rho GTPase Cdc42p [28]. Like Ras2p, Cdc42p is a monomeric GTPase of the RAS superfamily. When activated by GTP binding, Cdc42p interacts with the 
serine/threonine p21 activated kinase (PAK) Ste20p, which controls a MAP kinase cascade consisting of Ste11p (MAPKKK), Ste7p (MAPKK), and Kss1p (MAP kinase) (Figure 1) [29]. Kss1p phosphorylates and activates the transcription factors Ste12p and Tec1p, which bind to so called "Filamentation and invasive Response Elements". These consensus sequences are found in the promoter regions of several genes that are necessary for filamentous growth $[27,30]$. Many of the pathways that regulate filamentous growth can influence each other's activities. For example, Ras2p regulates the activity of the fMAPK pathway [31].
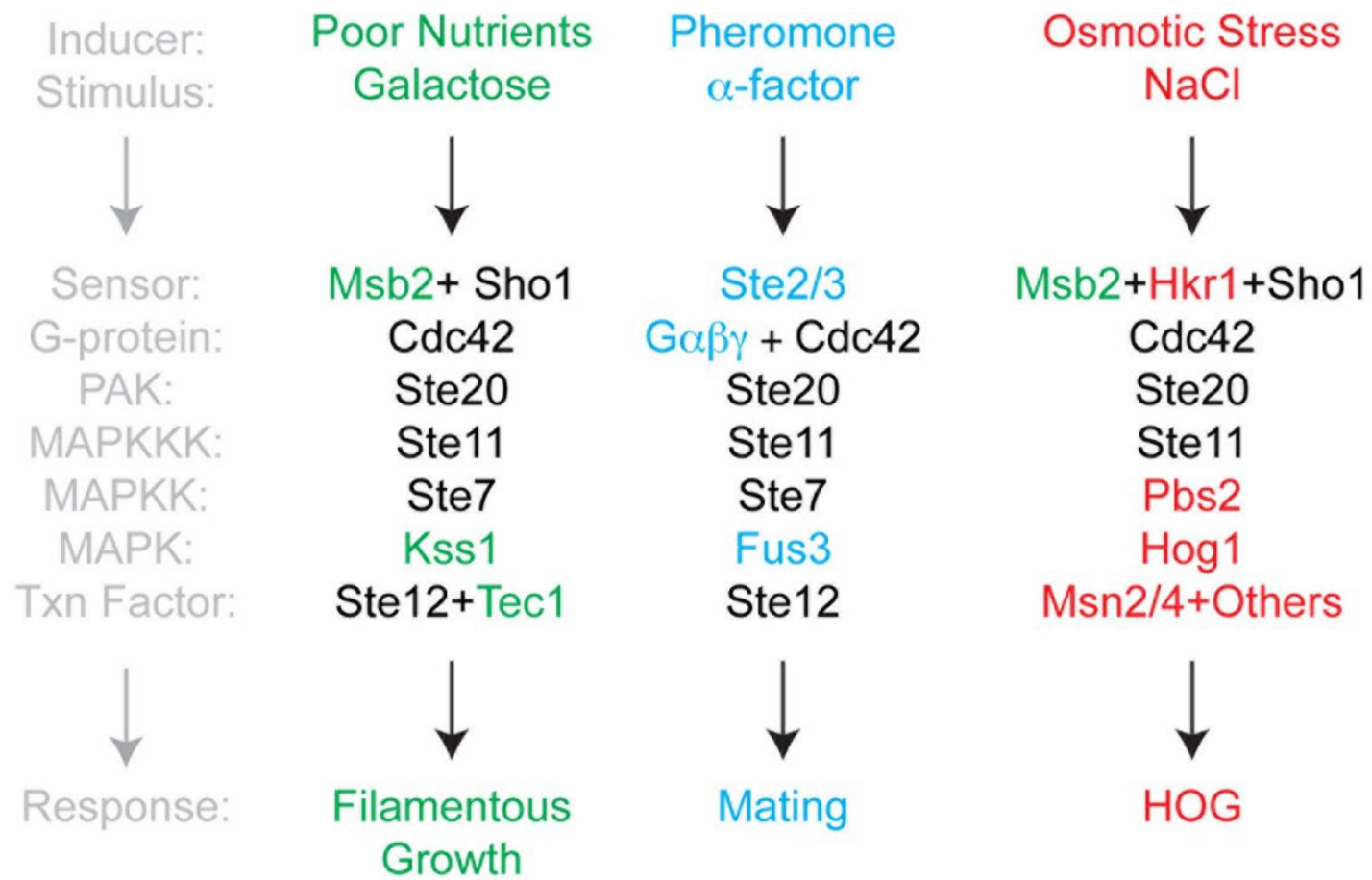

Figure 1. Cdc42-dependent MAPK pathways in yeast. Three yeast MAPK pathways share components, yet induce different responses to different stimuli. Pathway components common to multiple pathways are shown in black. Pathway-specific proteins are colored (red letters: hyperosmolarity glycerol response (HOG) pathway; blue letters: pheromone response; green letters: filamentous growth). Not all components are shown.

The MAP kinase pathway that regulates filamentous growth is composed of proteins that can also function in other MAP kinase pathways in the same cell (Figure 1). Many of the proteins, including Cdc42p, Ste20p, Ste11p, and Ste7p also regulate the mating or pheromone response pathway [32]. The mating pathway is required for haploid cells of complementary cell types to form diploids. During mating, cells express peptide pheromones (a- and alpha-factor) that are recognized by G-protein coupled receptors (GPCR, Ste2p, and Ste3p) on complementary cell types. Detection of pheromone by receptor leads to transcriptional induction of target genes, cell cycle arrest, and morphogenetic changes that prepare the cell to interact with its mating partner. Fusion of the two cell types leads to the formation of a diploid cell. One response of yeast cells that come into contact with pheromones is a morphological change known as shmoo. The formation of shmoos is mainly driven by the actin cytoskeleton: actin patches are concentrated in the shmoo tip, whereas actin cables can be found alongside the axis of polarization [33]. This is a further connecting link to filamentous growth in which primarily actin patches play an important part and are mostly polarized to the distal tip of the outwardly growing cell [20]. It has previously been shown that addition of non-physiological concentrations of alpha factor induce a burst of ROS production after $1.5 \mathrm{~h}$ accompanied with apoptotic cell death after $3.5 \mathrm{~h}$. Under native conditions (mixing a with alpha cells) this phenomenon was observed at reduced levels ( $30 \%$ of all cells) [34]. 
In addition to mating and filamentous growth, Cdc42p, Ste20p, and Ste11p proteins also regulate one of two redundant branches of the p38-type hyperosmolarity glycerol response (HOG) pathway, which mediates the tolerance to osmotic stress (Figure 1) [35]. In the HOG pathway, two mucin-type glycoproteins function as sensors, one being Msb2p, which also functions in the fMAPK pathway and the other, Hk1p, which does not [36-39]. These proteins along with the adaptor Sho1p regulate Cdc42p, Ste20p, and Ste11p, which in turn regulates the MAPKK Pbs2p to control the activity of the MAP kinase Hog1p. Hog1p regulates at least five transcription factors: Msn2p, Msn4p, Hot1p, Sko1, and Smp1p [40]. A potential target of Msn2p is YNO1, which suggests that Yno1p might play a role in the osmotic stress response [41]. Therefore, signaling pathways can share components yet induce different responses, which can be critical for the response to stress and cell differentiation. Among the responses to osmotic stress are fragmentation of the vacuole and disruption of the actin cytoskeleton (for a detailed review see [40]). Vacuolar morphology is highly dynamic, and the underlying fission and fusion events are dependent on actin polymerization, which is also mediated by Cdc42p [42]. During vegetative growth, two to three vacuoles exist in yeast cells at the same time. Hypotonic conditions initiate vacuole fusion leading to a large vacuole, whereas salt stress initiates vacuole fission resulting in vacuole fragmentation [43].

In the present study, we explore how Ynolp might impact signaling functions during osmotic stress, pheromone response, and filamentous/invasive growth. We show that Yno1p impacts aspects of these processes in distinct ways. One way in which Yno1p might impact these processes is by its ability to regulate the actin cytoskeleton. Because morphogenetic processes and signaling events require a proper functioning actin cytoskeleton, Yno1p may integrate ROS signals by this mechanism. Therefore, ROS generation may be an important part of the cellular response to diverse stimuli.

\section{Material and Methods}

\subsection{Strains and Media}

All strains used in the study are either based on S. cerevisiae strains BY4741 (MATa his $3 \Delta 1$ leu $2 \Delta 0$ met $15 \Delta 0$ ura $3 \Delta 0), B Y 4742$ (MAT $\alpha$ his $3 \Delta 1$ leu $2 \Delta 0$ lys $2 \Delta 0$ ura3 $\Delta 0$ ) [44], or $\Sigma 1278$ b (MAT $\alpha$; ura3-52; trp1 $\Delta::$ hisG; leu2 $\Delta::$ hisG; his $3 \Delta::$ hisG) [45,46]. For details on strains used in this study, their construction, as well as media composition in which the strains were grown, see Supplementary Material and Methods.

\subsection{Cloning Experiments}

The expression vector p416GPD was used in the study. The LAS17 open reading frame was amplified by PCR from genomic yeast DNA by using Phusion ${ }^{\circledR}$ High-Fidelity DNA Polymerase (NEB, Ipswich, MA, USA) using the following primers: LAS17 forward (5'-CGG GAT CCA TGG GAC TCC TAA ACT C-3') and LAS17 reverse (5'-CCG CTC GAG TCA CTT ATC GTC ATC CTT GTA ATC CCA ATC ACC ATT GT-3'). The resulting PCR product was cloned into the vector using BamHI and XhoI (NEB, Ipswich, MA, USA). Successful cloning was confirmed by sequencing at Eurofins-MWG-OPERON.

\subsection{DHE Measurements}

The dihydroethidium (DHE) assay was performed as described in [47]. The yeast strains were grown for $16 \mathrm{~h}$ in liquid SC-glucose. Cells were collected by centrifugation (5000 rpm 2') and washed twice with $1 \times$ PBS (phosphate buffered saline). Approximately $5 \times 10^{6}$ cells were resuspended in $180 \mu \mathrm{L} 1 \times$ PBS containing $5 \mu \mathrm{g} / \mathrm{mL}$ DHE (Sigma-Aldrich/Merck, Darmstadt, Germany) and incubated for $15 \mathrm{~min}$ in the dark. DHE fluorescence was determined using an Anthos Zenyth 3100 plate reader (excitation: $485 \mathrm{~nm}$; emission: $595 \mathrm{~nm}$ ). Cell numbers were determined with an electric field multichannel cell counting system (CASY ${ }^{\mathrm{TM}}$; Schärfe; Germany). 


\subsection{Reporter Measurements}

Cells were washed twice in $1 \times$ PBS and $5 \times 10^{6}$ cells were resuspended in $200 \mu \mathrm{L}$ $1 \times$ PBS. GFP (green fluorescence protein) fluorescence was determined using an Anthos Zenyth 3100 plate reader (excitation: $485 \mathrm{~nm}$; emission: $535 \mathrm{~nm}$ ) as described [48]. The autofluorescence (cells without GFP expression) was subtracted from the signal reported. For experiments with wiskostatin (racemate) (Calbiochem/Sigma-Aldrich, Merck, Darmstadt, Germany), cells were grown for $18 \mathrm{~h}$ in liquid SC (synthetic complete) medium; $200 \mu \mathrm{M}$ wiskostatin was added for 3-4 h. For experiments with isoamyl alcohol (IAA), cells were diluted to an $\mathrm{OD}_{600}$ (optical density at a wavelenght of $600 \mathrm{~nm}$ ) $=0.1$ in liquid YEPD (yeast extract peptone dextrose) medium. Moreover, IAA $(0.5 \%)$ was added, and cells were grown for 36-48 h. To evaluate osmotic stress, cells were diluted to an $\mathrm{OD}_{600}=0.1$ in liquid YEPD medium. A total of $1 \mathrm{M} \mathrm{NaCl}$ was added and cells were grown for 36-48 h. To evaluate filamentous growth, a preculture was grown in SC-raffinose (3\%). Cells were diluted to an $\mathrm{OD}_{600}=0.1 \mathrm{in} \mathrm{SC}$-galactose (3\%) and grown for $36 \mathrm{~h}$.

\subsection{Spot Test Assay}

Yeast strains (control; single and double gene deletions) were grown in liquid SCglucose medium at $24{ }^{\circ} \mathrm{C}$ until stationary phase. Cells were diluted to $\mathrm{OD}_{600}$ values of 3.0, 1.0, 0.3, and 0.1. SC-glucose semi-solid agar medium was prepared containing wiskostatin in a range from 10 to $20 \mu \mathrm{M}$. To semi-solid agar media, $10 \mu \mathrm{L}$ aliquots of the diluted yeast strains were spotted. Plates were incubated for $3-4$ days at $24^{\circ} \mathrm{C}$.

\subsection{Assays to Evaluate Filamentous/Invasive Growth}

The plate-washing assay was performed as described [22]. The single-cell invasive growth assay was performed as described [49]. Differential interference contrast (DIC) microscopy was performed with an Axioplan 2 fluorescent microscope (Zeiss, Oberkochen, Germany) with a Plan-Apochromat 100X/1.4 (oil) objective (N.A. 1.4) (cover slip 0.17) (Zeiss, Oberkochen, Germany). Cells were examined at multiple focal planes with an Axiocam MRm camera (Zeiss, Oberkochen, Germany) and AxioVision 4.4 software (Zeiss, Oberkochen, Germany). Adjustments to contrast and brightness were performed using Adobe Photoshop (Adobe, San Jose, CA, USA). ImageJ analysis (http:/ / rsb.info.nih.gov/ $\mathrm{ij} /$ ) was used to quantitate invasive growth [50]. Background intensity was determined for each spot and subtracted from the densitometry of the area of invaded cells. Invasive growth assays were performed in biological replicates $(\mathrm{N}>3)$. The variation in between samples was typically less than $15 \%$ across trials, as assessed by independent quantitation methods, ImageJ and OpenLab Software.

\subsection{Immunoblot Analysis}

Immunoblots were performed as described [51]. Proteins were prepared from cell extracts from cells grown under the indicated conditions and analyzed by sodium-dodecylsulfate (SDS) polyacrylamide gel electrophoresis (PAGE), using 10\% acrylamide in the running gels. Proteins were transferred from gels to nitrocellulose membranes that were probed with the indicated antibodies. Antibodies that recognize GFP (\#11814460001, clones 7.1 and 13.1, Roche) were used at 1:1000 dilution. Antibodies that recognize Pgk1p (Life Technologies; Camarillo, CA, USA; Cat \#459250) were used at 1:10,000 dilution. Secondary antibodies goat anti-mouse IgG-HRP (Bio-Rad Laboratories, Hercules, CA, USA; Cat \#1706516) were used for detection of primary antibodies. Band intensity was measured by Image Lab Software (Bio-Rad, Hercules, USA) using unsaturated exposures. Background subtraction was performed based on the software user guidelines. Band intensities were compared to total protein levels based on Pgk1p levels.

\subsection{Osmotic Stress and FM4-64 Staining}

FM4-64 staining with small modifications was performed as described [52]. Yeast cells were diluted to an $\mathrm{OD}_{600}=0.1$ and were grown for $12 \mathrm{~h}$ in liquid SC-medium. An aliquot 
$(2 \mathrm{~mL})$ was washed once in YEPD and resuspended in $100 \mu \mathrm{L}$ YEPD supplemented with $20 \mu \mathrm{M}$ FM4-64. After a $20 \mathrm{~min}$ incubation at $28^{\circ} \mathrm{C}$, cells were wash with SC-medium and incubated for $1 \mathrm{~h}$ in $100 \mu \mathrm{L}$ liquid SC medium. Moreover, $50 \mu \mathrm{L}$ of this cell suspension was used as a control, $50 \mu \mathrm{L}$ was supplemented with $1 \mathrm{M} \mathrm{NaCl}$ and incubated for $>30 \mathrm{~min}$. Cells stained by FM4-64 were analyzed with a $\times 100$ objective $(\mathrm{NA}=1.4)$ using either a Carl Zeiss AG Axioscope (Oberkochen, Germany) or a Nikon (Tokyo, Japan) Eclipse Ni-U equipped with a DS-Fi2 digital camera.

\subsection{Pheromone Response Assay}

Cells were grown to late exponential phase in liquid SC medium. Shmooing and apoptotic cell death was induced by the addition of $100 \mu \mathrm{g} / \mathrm{mL}$ alpha-factor (GenScript, Piscataway, NJ, USA). After incubation for $4 \mathrm{~h}$ at $28{ }^{\circ} \mathrm{C}$ under constant shaking, the appearance of shmoos was evaluated by light microscopy. Cell survival was calculated by plating 500 cells on YEPD medium and counting the number of colonies after 3 days of incubation at $28^{\circ} \mathrm{C}$.

\subsection{Actin Morphology}

Cells were cultivated in $3 \mathrm{~mL}$ of SC-Ura media in 6-well plates. The cell suspension was then mixed with fresh SC-Ura medium (1:1) and galactose up to $3 \%$ was added after $1 \mathrm{~h}$ precultivation. The cells were inspected in the cultivation medium, mounted on a glass slide, covered with a coverslip, and directly imaged at room temperature. Only the first three snapshots of each sample were used for analysis. The distribution of TagRFP-T was analyzed with a 100x Plan Apochromat objective (NA = 1.4). An Olympus IX-81 inverted microscope (Tokyo, Japan) equipped with a Hamamatsu Orca/ER digital camera and the Olympus Cell RTM detection and analyzing system was used. TagRFP-T fusion was detected using RFP filter block (U-MWIY2, excitation; 545-580 nm; emission $610 \mathrm{~nm}$ ). Images were processed and merged using Olympus Cell RTM (xcellence RT) and Adobe CS6 software. Images presented as Z-stack are maximal projections of stacks obtained using a $0.4-\mu \mathrm{m}$ steps. Images presented as T-stacks are minimum intensity projection of fluorescence from 15 captured frames. Deconvolution of images obtained by Z-sectioning was done by Wiener filter (WF). Time lapse settings: The image acquisition parameters of T-stack in Figure 9 were one frame per $5 \mathrm{~s}$ (fifteen frames in total), and in supplementary movies, one frame per $5 \mathrm{~s}$ (fifty frames in total).

\subsection{Statistical Analysis}

Data are presented as arithmetic means \pm S.D. We used a one-way ANOVA test including Tukey HSD (honestly significant difference) and a student's t-test for statistical analysis. Results with a $p<0.05$ were considered to be statistically significant.

\subsection{Gene Accession Numbers}

YNO1: S000003128; HOT1: S000004783; KSS1: S000003272; RAS2: S000005042; ARP2: S000002187; ARP3: S000003826; ABP140: S000005765; CDC42: S000004219; PBS2: S000003664; STE7: S000002318; BEM2: S000000957; TEC1: S000000287; RIM101: S000001019; STE11: S000004354; SMP1: S000000386; STE12: S000001126; SNF1: S000002885; LAS17: S000005707; NRG2: S000000270; NRG1: S000002450; MSN2: S000004640; SOD1: S000003865; HOG1: S000004103; MSB2: S000003246; VRP1: S000004329; YCK1: S000001177; YCK2: S000005098; STE20: S000000999; SKO1: S000005111

\section{Results}

\subsection{Establishment of an YNO1 Expression Reporter}

In a previous study [5], we have shown that the ROS produced by the NADPH oxidase Yno1p at physiological levels are not harmful for the cell, but act primarily as signaling molecules. Moreover, overproduction of the Ynolp protein, which induces a burst of ROS, resulted in the induction of apoptotic cell death [5]. To gain further insight into the 
pathways that may be regulated by Yno1p, an expression reporter was constructed. The YNO1 ORF was replaced by GFP; thus, placing the fluorescent protein under control of the native YNO1 promoter (PYNO1 $\triangle y$ no1::GFP-HIS3). The necessary genetic manipulations are summarized in the Supplementary Material and Methods section, and the resulting genetic alterations on chromosome VII are shown in Supplementary Figure S1.

The YNO1 expression reporter was tested under three well-defined settings. One setting was cells lacking mtDNA. It is well established that a rho0 petite yeast strain (a strain completely devoid of mtDNA) shows reduced ROS production [53-55]. By using a dihydroethidium (DHE) assay, ROS levels were compared between the rho0 strain and the corresponding wild type strain. DHE was initially used as a superoxide specific probe, but recently it was shown that this dye can be oxidized by hydrogen peroxide in the presence of heme proteins [56]. By this test, the rho0 strain showed reduced levels of ROS production (Figure 2A). The DHE fluorescence signal in the petite strain was more than $80 \%$ decreased. Currently, it is assumed that complex III of the respiratory chain is responsible for $80 \%$ of the cellular superoxide levels in yeast cells [54]. Surprisingly, the ROS levels in petite strains correlated well with the expression of Ynolp. The wild type strain showed a 5-fold higher expression of $\mathrm{P}_{Y N O 1} \Delta y n o 1:: G F P-H I S 3$ than the non-respiring strain (Figure 2B). This result indicates that cross talk occurs between the mitochondria and the expression of the gene encoding NADPH oxidase. This phenomenon of ROS-induced ROS has been described in other model systems [57,58]. Previously, we and others have demonstrated that Yno1p contributes to $20 \%$ of the cellular superoxide levels under normal growth conditions $[5,8,15,59]$. As shown below, an increase in Ynolp expression accompanied by an increase in ROS production is needed under well-defined cellular settings.

The second condition was in cells experiencing ER stress. It has been established that Yno1p protein levels are controlled by the endoplasmic reticulum-associated degradation (ERAD) pathway. After a diauxic shift, Yno1p levels were absent at the ER [15]. By the Yno1p reporter system, we found that the expression of YNO1 was quite stable during exponential growth and leads to a burst of expression in early stationary phase ( $\sim 70 \mathrm{~h}$ of growth). After $100 \mathrm{~h}$, the GFP signal significantly decreases (Figure 2C). This discrepancy to the data presented in Leadsham at al. [15] could be explained by the fact that the Yno1p itself may be specifically turned over by the ERAD system, whereas GFP is quite stable. GFP may therefore be a useful reporter for switch-on (inducing), but not switch-off (repressing) conditions [60].

The third condition was experiments interrogating the actin cytoskeleton. We have previously shown that a $\triangle y n o 1$ strain is sensitive to the addition of wiskostatin [5]. Wiskostatin was shown to interact with the evolutionary highly conserved protein N-WASp (isolated from Xenopus laevis eggs) thus interfering with F-actin polymerization [61]. Treating cells harboring the Yno1p reporter with wiskostatin led to an increase in GFP signal. Several wiskostatin concentrations were tested in a range from $50-300 \mu \mathrm{m}$ wiskostatin and a peak was reached at a concentration of $150-200 \mu \mathrm{M}$ with a $>60 \%$ increase in GFP fluorescence. In a petite strain, the difference was even more striking, which showed an $\sim$-fold increase in the expression of the $\mathrm{P}_{Y N O 1} \Delta y n o 1:: G F P-H I S 3$ construct (Figure 2D). Under the described conditions, addition of either 0.5 or $1 \mathrm{mM} \mathrm{H}_{2} \mathrm{O}_{2}$ reduced the expression of GFP to the same levels as seen in control cells (Figure 2E). 

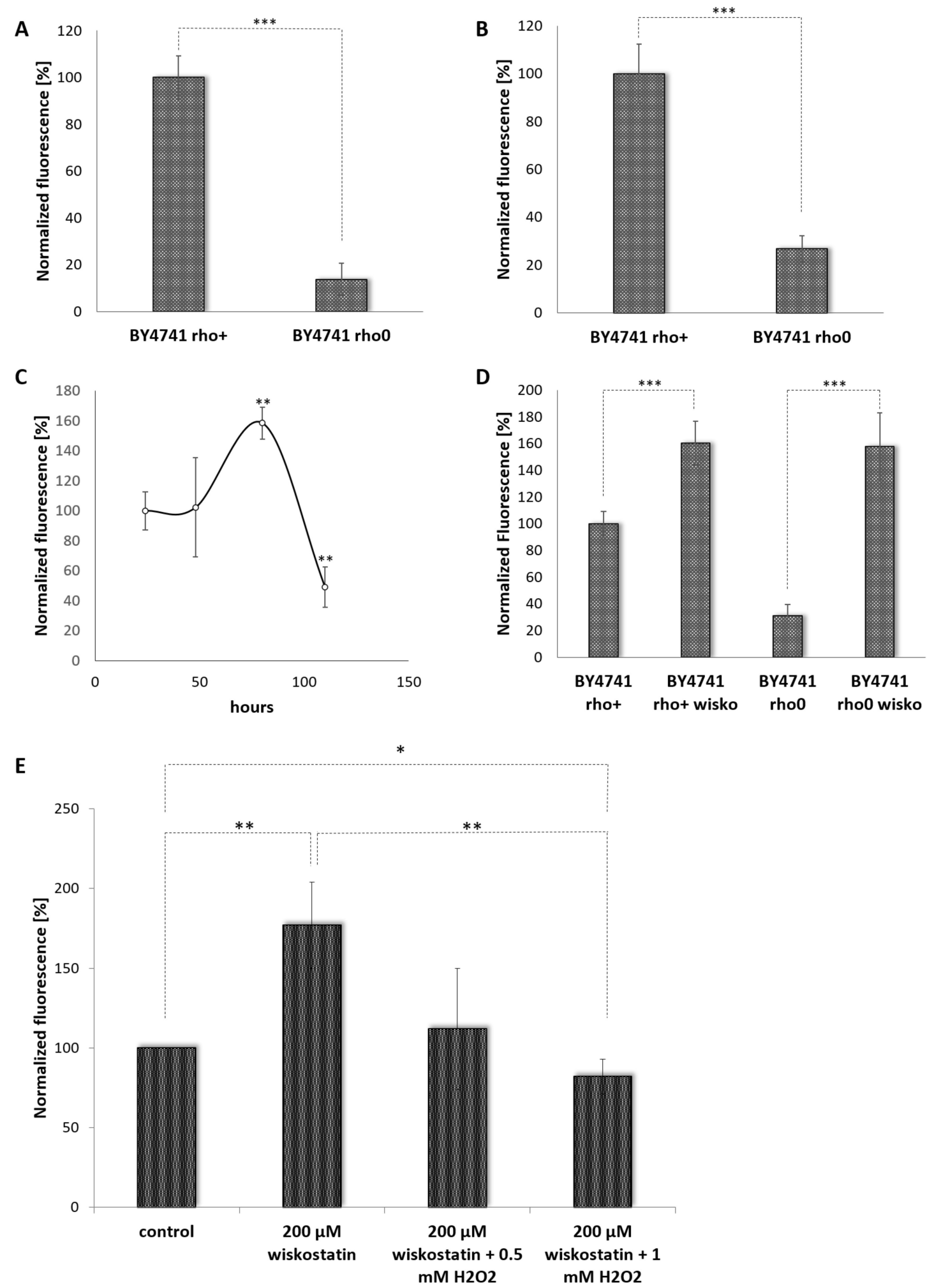

Figure 2. A GFP-based YNO1-reporter. (A) Superoxide levels were measured by using the fluorescent probe DHE. The wild type strain BY4741 ( $\mathrm{rho}^{+}$) and the petite strain BY4741 (rho0) were analyzed (N = 4-7). In (B-E), the expression of $Y N O 1$ was studied by measuring GFP fluorescence. A GFP-HIS3 cassette was used to replace the native YNO1 ORF. In (B), the strains BY4741 $\Delta$ yno1::GFP-HIS3 rho+ and BY4741 $\triangle$ yno1::GFP-HIS3 rho0 were compared $(\mathrm{N}=6)$. In $(\mathrm{C})$, the expression of $Y N O 1$ was analyzed at the transition from late exponential phase to early stationary and stationary phase in the strain BY4741 $\triangle$ yno1::GFP-HIS3 $(\mathrm{N}=4)$. (D) shows the expression of YNO1 in the strains BY4741 $\Delta$ yno1::GFP-HIS3 rho+ and BY4741 $\Delta$ yno1::GFP-HIS3 rho0 after addition of $200 \mu \mathrm{M}$ wiskostatin (wisko, $\mathrm{N}=4$ ). In $(\mathbf{E})$, wiskostatin $(200 \mu \mathrm{M}$ )-induced expression of YNO1 is reversed by addition of $0.5 \mathrm{mM}$ or $1 \mathrm{mM} \mathrm{H}_{2} \mathrm{O}_{2}(\mathrm{~N}=4)\left({ }^{*}: p<0.1 ;{ }^{* *}: p<0.05 ;{ }^{* *}: p<0.01\right)$. 
To define how Yno1p might impact polymerization of F-actin, a spot test was performed. Serial dilutions of yeast cells were spotted on SC plates containing $20 \mu \mathrm{M}$ wiskostatin and incubated for 3-4 days at $24{ }^{\circ} \mathrm{C}$, which was permissive for growth for the temperature-sensitive strains tested. Under the conditions examined, the $\Delta$ las 17 and $\Delta$ vrp 1 strains showed slow growth at $28^{\circ} \mathrm{C}$, and the $\Delta$ las $17 \Delta v r p 1$ double deletion strain was not viable. Confirming previous results, deletion of $Y N O 1$ also led to sensitivity to wiskostatin. The yeast homologue of N-WASp is Las17p, which together with the Arp2/3 complex, promotes the nucleation of branched actin filaments [59]. Surprisingly, deletion of the proposed target of wiskostatin, Las17p, made the cells hypersensitive to the addition of $20 \mu \mathrm{M}$ of wiskostatin (Figure 3). Therefore, it can be excluded that the N-WASp inhibitor solely binds to Las17p in yeast cells and may indicate that there is at least one other interacting partner. A likely candidate for the binding of wiskostatin is Vrp1p (verprolin; very proline-rich). Vrp1p binds to the $\mathrm{N}$-terminal region of Las17p, which is also rich in proline, and together the two proteins activate the Arp2p/3p complex [62]. Both Vrp1p and Las17p promote the nucleation of F-actin independently of the Arp2/3 complex [63]. In fact, wiskostatin had only a modest effect on growth of the $\Delta v r p 1$ strain. A $\Delta y n o 1 \Delta v r p 1$ double deletion strongly amplified the wiskostatin sensitivity compared to the corresponding single deletions. By reducing the wiskostatin concentration, the $\Delta$ las 17 showed growth compared to the $\Delta l a s 17 \Delta y n o 1$ double deletion strain.

\section{Ctrl wiskostatin}

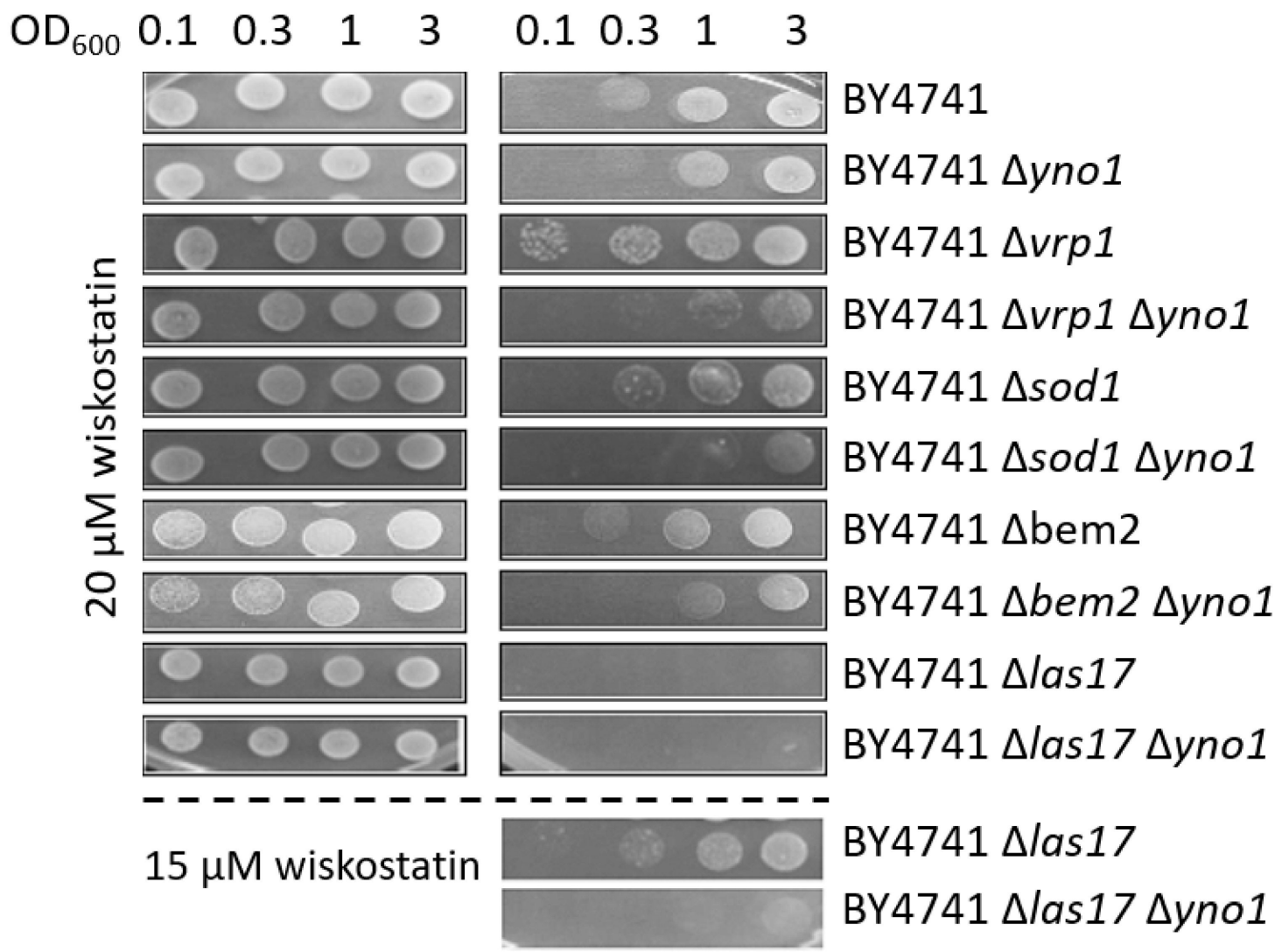

Figure 3. The sensitivity of mutants to wiskostatin by spot test analysis. Serial dilutions $\left(\mathrm{OD}_{600}\right.$ of $3,1,0.3$, and 0.1$)$ of the

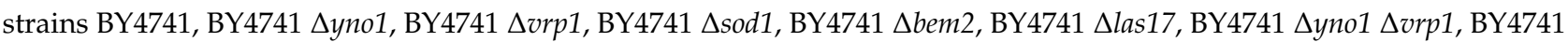
$\Delta y n o 1 \Delta$ sod1, BY4741 $\Delta y n o 1 \Delta b e m 2$, and BY4741 $\Delta y n o 1 \Delta$ las17 were spotted on SC-glucose plates, SC-glucose $+20 \mu \mathrm{M}$ wiskostatin plates and SC-glucose $+15 \mu \mathrm{M}$ wiskostatin plates. At least three biological replicates were tested on plates containing concentrations of wiskostatin in a range from 0-100 $\mu \mathrm{M}$. Representative images and concentrations were chosen. 
Directly upstream in the pathway that regulates Las17p is the Rho GTPase Cdc42p. This GTPase is essential, therefore a $\Delta b e m 2$ strain was analyzed. Bem2p is the GAP of $C d c 42 p$ and upon its deletion the activity of Cdc42p is disturbed. A double deletion strain of BEM2 and YNO1 was hyper-sensitive to wiskostatin and showed a slower growth on plates containing wiskostatin than the appropriate single gene deletions. Yno1p itself is not capable of producing the signaling molecule hydrogen peroxide and is therefore most probably dependent on the superoxide dismutase Sod1p [8]. This assumption was tested by using a $\Delta y n o 1 \Delta$ sod1 double deletion strain that showed a high sensitivity to wiskostatin. If any, the phenotype of a SOD1 single gene deletion was modest. A further downstream target of Cdc42p is the PAK Ste20p that mediates osmotic stress response [64], pheromone response [65] and filamentous growth [27]. These three pathways will be studied below.

\subsection{Yno1p and the Osmotic Stress Response}

It has been reported that salt stress interferes with the cell cycle, leading to growth arrest and ultimately the apoptosis of yeast cells [66]. In subsequent studies, it was shown that in this case programmed cell death is not accompanied by increased ROS levels. Such elevated ROS levels were only observed in specific deletion mutants (e.g., a $\Delta s r o 7$ strain) [67]. Our analysis confirmed this finding. Addition of $1 \mathrm{M} \mathrm{NaCl}$ did not lead to a significant increase in superoxide levels in the BY4741 background (Figure 4A). In contrast to the situation in the wild type strain, the absence of mitochondrial DNA and, thus, mitochondrial respiration led to a high response to the addition of $\mathrm{NaCl}$.

The addition of $1 \mathrm{M} \mathrm{NaCl}$ increased the amount of ROS in the strain BY4741 rho0 by $>17$-fold. Under these conditions, the amount of ROS in the petite strain surpassed superoxide levels in untreated wild type cells. The increase of $\mathrm{ROS}$ upon $\mathrm{NaCl}$ treatment was largely dependent on the yeast NADPH oxidase. Deletion of YNO1 in the petite background led to a strong reduction in ROS levels, although a non-statistical significant increase was still observed. These findings were also mimicked by the YNO1 reporter expression: no increase in PYNO1 yyno1::GFP-HIS3 expression was observed in the rho ${ }^{+}$ background, whereas a 3-fold expression was found in the rho0 background upon addition of $1 \mathrm{M} \mathrm{NaCl}$ (Figure 4B). In a petite strain also lower concentrations of $\mathrm{NaCl}(0.5 \mathrm{mM}$ and $0.7 \mathrm{mM}$ ) induced an expression of Yno1p albeit on reduced levels.

We next sought to test whether the osmotic stress induced Yno1p expression is dependent on the Cdc42p/Ste20p proteins. Cdc42p and its effector Ste20p regulate one branch of the HOG pathway (Figure 1) [40,64]. Interestingly, in cells lacking Ste20p, the increase in GFP-signal by $\mathrm{NaCl}$ did not occur. Another protein that is important in coping with osmotic stress is Msn2p. This is a cytosol-localized transcription factor that upon stress induction translocates to the nucleus and mediates the expression of stress response genes $[68,69]$. It is predicted that this transcription factor also binds to the promoter region of YNO1 [41,70]. During osmotic stress, Msn2p migrates to the nucleus (after 8 $\mathrm{min}$ ) shuttles back to the cytosol presumably once cellular adaptation occurs (after $15 \mathrm{~min}$ ) [71]. Deletion of MSN2 also abolished the increase in YNO1 expression during salt stress (Figure 4B). Another predictor for the change in osmolarity is vacuolar morphology. In the BY4741 background, these changes in vacuolar morphology are transient [52]. To assay mitochondrial morphology BY4741 and the BY4741 $\Delta y n o 1$ mutant, cells were prestained with the dye, FM4-64 [72]. FM4-64 is a lipophilic dye that intercalates into the plasma membrane, and after internalization by endocytic events, stains the vacuolar membrane and other internal compartments. In most untreated control cells (Figure 4C), three distinct vacuoles were observed. The addition of $0.4 \mathrm{M} \mathrm{NaCl}$ induced fragmentation of vacuoles after $10 \mathrm{~min}$. By $20 \mathrm{~min}$ and until cells adapted to stress, the fragmented vacuoles underwent fusion. In cells lacking YNO1, untreated cells showed a higher fragmentation of vacuoles, although on a very subtle level. Similar to wild type cells, addition of $\mathrm{NaCl}$ resulted in a complete fragmentation of vacuoles. After $30 \mathrm{~min}$ of incubation, no sign of adaptation was observed in the $\Delta y n o 1$ background, and it took another $30 \mathrm{~min}$ until the vacuoles started to revert back to the normal phenotype. 


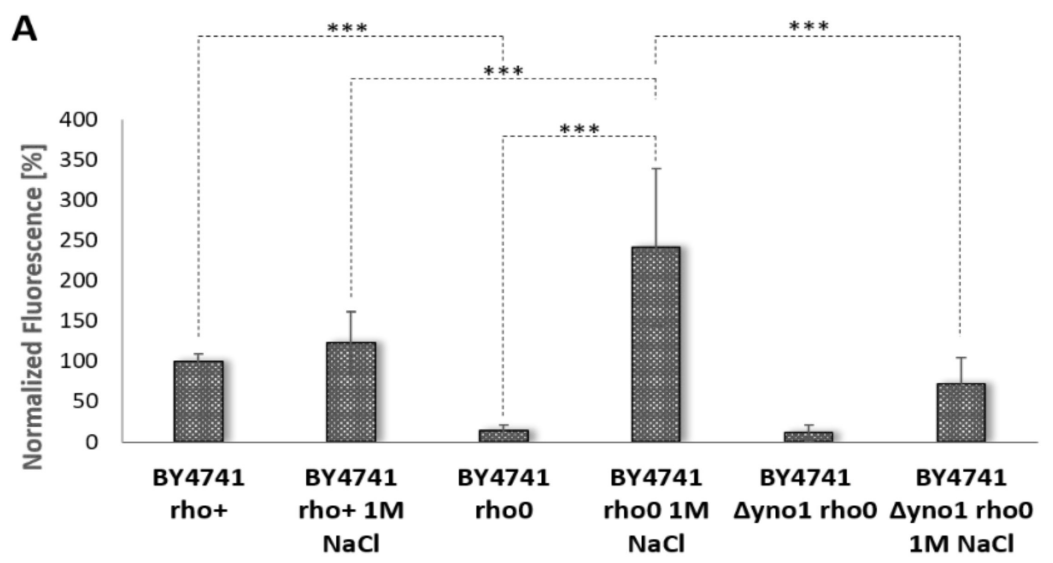

B

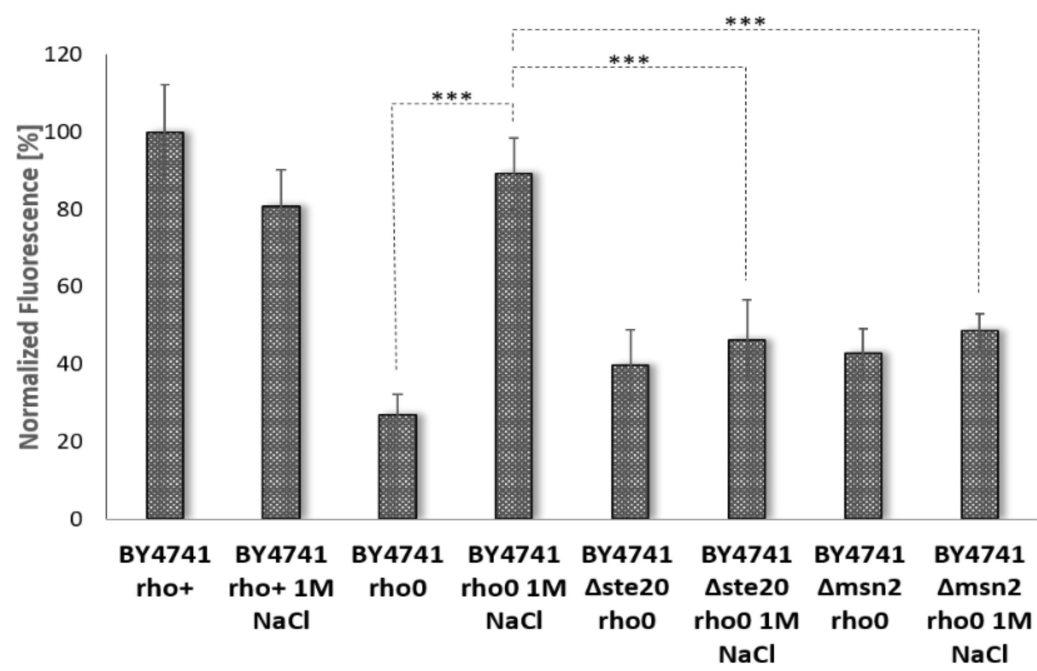

C

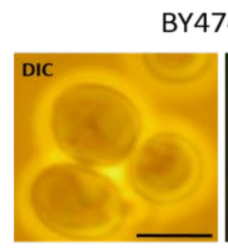

Y4741

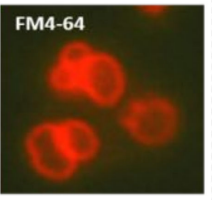

BY4741 $\Delta y n o 1$
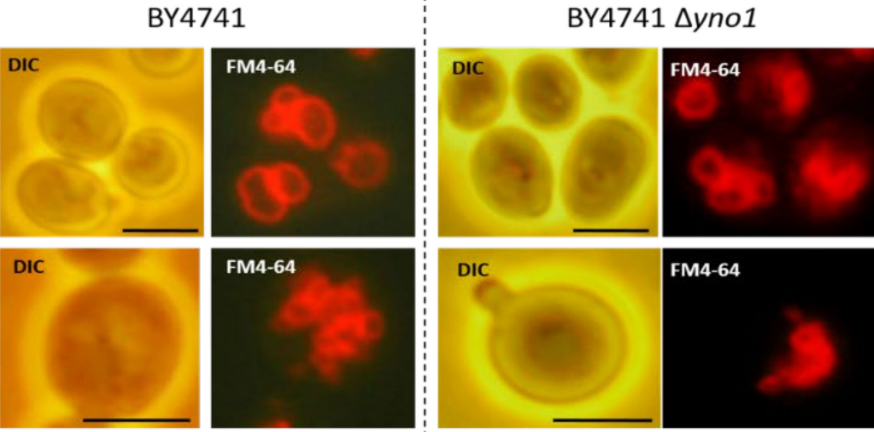

ctrl
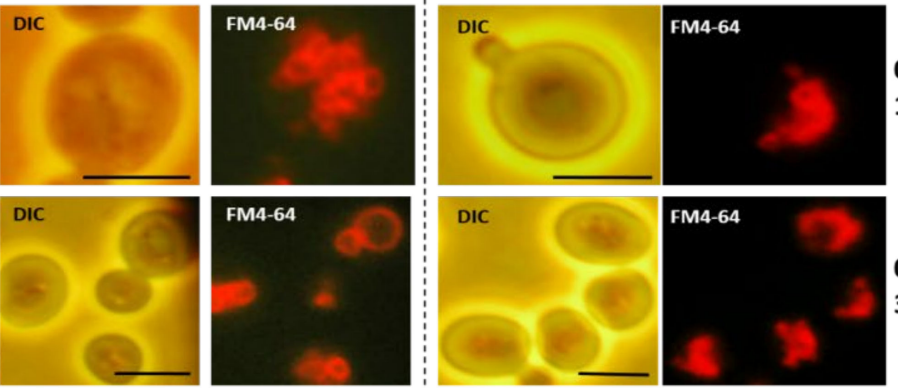

$0.4 \mathrm{M} \mathrm{NaCl}$

$10 \mathrm{~min}$

Figure 4. YNO1 reporter levels and vacuolar morphology in response to osmotic stress. (A) Superoxide levels were measured using the dye DHE in the strains BY4741 rho+, BY4741 rho0, and BY4741 $\Delta y n o 1$ rho0 ( $\mathrm{N}=4-7)$. In (B) the YNO1 expression in the strains BY4741 rho+, BY4741 rho0, BY4741 $\Delta s t e 20$ rho0 and BY4741 $\Delta m s n 2$ rho0 was measured using a GFP-reporter $(\mathrm{N}=4-6)$. In $(\mathbf{A})$ and $(\mathbf{B})$, osmotic stress response was induced by the addition of $1 \mathrm{M} \mathrm{NaCl}\left({ }^{* * *}: p<0.01\right)$. In $(\mathbf{C})$, vacuolar membranes were stained with the lipophilic dye FM4-64. Osmotic stress was induced by addition of $0.4 \mathrm{M} \mathrm{NaCl}$. Scale bars represent $5 \mu \mathrm{m}$. The assay was performed in triplicate, and representative images are shown. 


\subsection{Yno1p and the Pheromone Response}

The addition of non-physiological concentrations of alpha-factor results in a burst of ROS production [34]. In fact, we found that most of the ROS produced in this setting was dependent on the yeast NADPH oxidase. The wild type strain BY4741 showed a $>2$-fold increase in DHE fluorescence after addition of $100 \mu \mathrm{g} / \mathrm{mL}$ alpha factor. In the $\Delta y n o 1$ strain a lower increase in ROS was observed (Figure 5A).

A
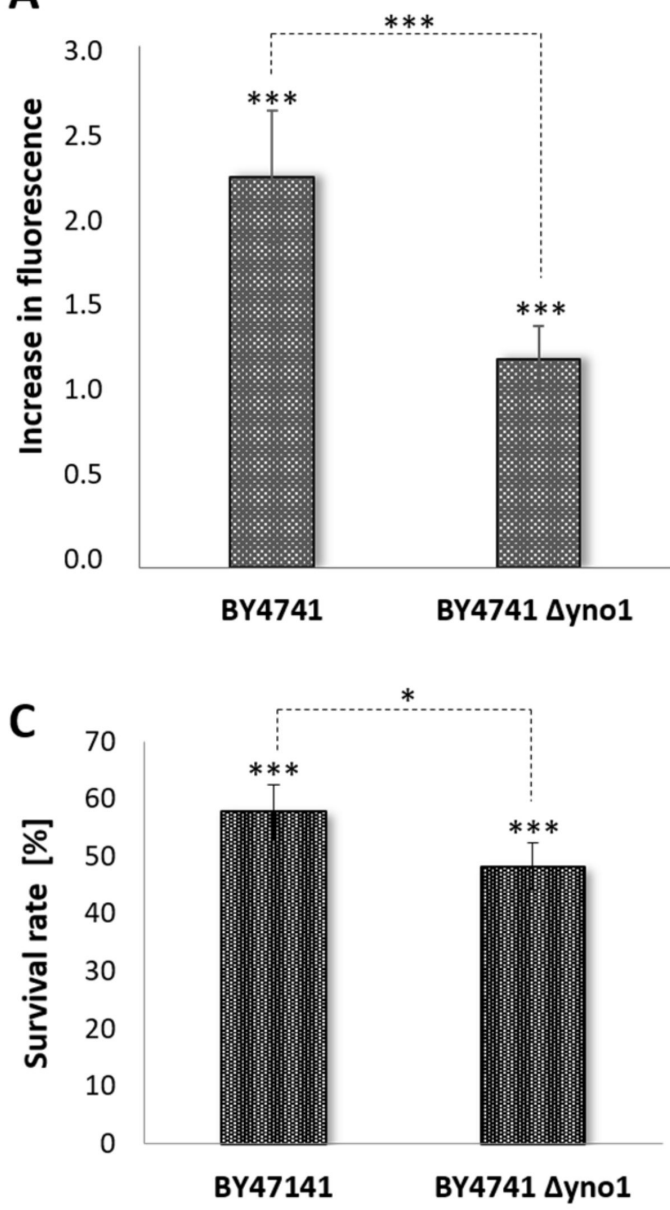

B

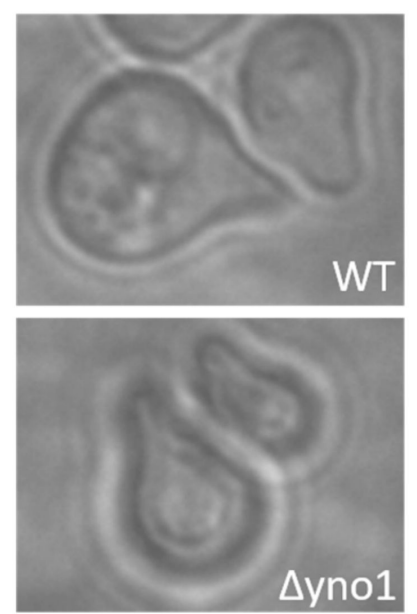

Figure 5. The role of Yno1p in pheromone response. (A) DHE fluorescence was analyzed in the strains BY4741 and BY4741 $\Delta y n o 1$ in untreated controls as well as after addition of alpha factor $(100 \mu \mathrm{g} / \mathrm{mL})(\mathrm{N}=8)$. In $(\mathbf{B})$, differential interference contrast microscopy images of shmoos in the BY4741 and BY4741 $\Delta y n o 1$ background are shown after addition of alpha factor $(100 \mu \mathrm{g} / \mathrm{mL})$. In (C), the survival rate in the strains BY4741 and BY4741 $\Delta y n o 1$ was calculated by survival plating. Cell death was induced by addition of alpha factor $(100 \mu \mathrm{g} / \mathrm{mL})$. In untreated cells (BY4741 and BY4741 $\Delta y n o 1)$, no difference in survival was observed. For $(\mathbf{A}, \mathbf{C})$ : each bar represents the comparison between untreated and treated yeast strains (either BY4741 or BY4741 $\Delta y n o 1$ ), asterisks above the bars indicate statistical significance between with/without treatment, asterisks above the brackets represent statistical significance between the different yeast strains (BY4741 and BY4741 $\Delta y n$ 1) upon treatment with alpha-factor $\left({ }^{*}: p<0.1 ;{ }^{* * *}: p<0.01\right)$.

Surprisingly, the formation of shmoos (Figure 5B) was not affected by a deletion of YNO1. Although the ROS level decreased in the $\Delta$ yno1 deletion background, the survival rate was not increased, but on the contrary slightly decreased when compared to the wild type (Figure 5C). Confirming the results of Severin and Hyman [34], an overdose of alpha factor initiates a process that kills approximately $50 \%$ of cells independent of the genetic background. 


\subsection{Evaluating the Role of Yno1p in Regulating Filamentous Growth}

In addition to regulating the HOG pathway and the response to pheromone, Cdc42p and Ste20p also regulate the filamentous growth pathway [46], which is one of the signaling pathways that induces invasive/filamentous growth in response to nutrient limitation [27]. Filamentous growth in yeast can be induced in several ways. "Fusel" alcohols, such as isoamyl alcohol (IAA), can induce filamentous growth [73,74], as does growth in nonpreferred carbon (e.g., galactose) [75] and nitrogen sources [46]. Both $0.5 \%$ isoamyl alcohol (IAA) (Figure 6A) and $2 \%$ galactose (Figure 6B) induced the Yno1p reporter (of $\mathrm{P}_{Y N O 1}$ $\Delta y n o 1:: G F P-H I S 3)$. To confirm this result, YNO1 was genomically tagged with GFP (BY4741 YNO1-GFP::HIS3) and analyzed by immunoblot analysis. Galactose or IAA treatment caused an increase in the level of Yno1p-GFP (2.5-fold and 9 fold, respectively) (Figure $6 \mathrm{C})$. Deletion of STE20 caused a reduction in Yno1p expression in SC-galactose media (Figure 6B). An Yno1p reporter signal was still detectable in the $\Delta$ ste20 background after addition of IAA. A downstream target of the yeast MAP kinase cascade consisting of several serine/threonine kinases (Ste20 $\rightarrow$ Ste11p $\rightarrow$ Ste7p $\rightarrow$ Kss1p) are the transcription factors Tec1p and Ste12p [27]. Similar to Msn2p, Ste12p is predicted to bind to the YNO1 promoter region $[41,76]$. Under the induction conditions tested (galactose and IAA), deletion of STE20 resulted in reduced YNO1 expression (Figure 6A,B). This result indicates that YNO1 expression may be regulated by the MAP kinase cascade that regulates filamentous growth.

Filamentous growth is accompanied by an elongated morphology that results from a delay in the G1 and G2-phases of the cell cycle, a change in cell polarity, and enhanced cell-cell adhesion mediated by the adhesion/flocculin Flo11p. Collectively, these and other changes promote increased invasion of cells into substrates [27,74]. Due to the fact that filamentous growth is strictly dependent on Flo11p [77], and endogenous FLO11 expression is low in BY4741 [78], the filamentous strain background $(\Sigma 1278 b)$ was chosen for further experiments [46]. The YNO1 gene was disrupted in an otherwise wild type filamentous strain by homologous recombination of a PCR-amplified KIURA3 cassette containing primer sequences to direct integration at the YNO1 locus. As a first test, the plate-washing assay [79] was performed to test the role of Yno1p in filamentous growth. Yeast cells can penetrate semi-solid agar media and are resistant to removal from agar plates by rinsing with water, by an assay called the plate-washing assay [22]. By this test, the $\Delta y n o 1$ strain was defective for invasive growth (Figure 7A).

The invasive growth defect of the $\Delta y n o 1$ strain was less severe than a strain lacking a functional MAP kinase cascade ( $\Delta$ ste 11 strain). The effects on cell morphology were also examined. Galactose-induced filamentous growth resulted in the formation of elongated cells in the wild type strain but not the $\Delta y n o 1$ mutant (Figure 7D). Cells overexpressing YNO1 were also examined. Wild type cells of the $\Sigma 1278 \mathrm{~b}$ background were transformed with a control plasmid, pYES2 or a plasmid that overexpresses YNO1, pYES2-YNO1 (for details see [5]). Compared to the strain harboring the empty vector (pYES2), the YNO1 overexpression construct (pYES2-YNO1) improved invasive growth (Figure 7B). The single cell invasive growth assay, which provides information about budding pattern and cell elongation [49], was also performed. Under conditions that induce filamentous growth (10 $\mu \mathrm{L}$ of $20 \%$ galactose plated on a SC-Ura medium), cells overexpressing YNO1 showed hyper-polarized cell morphologies (Figure 7E, arrows).

Based on the phenotypes on wiskostatin discussed above, we wanted to test if Ynolp might impact actin polymerization during filamentous growth and whether hydrogen peroxide plays some role. The LAS17 ORF was cloned into the vector p416GPD, which presumably results in high levels of the N-WASp homologue. This construct was introduced into wild type cells and the $\Delta y n o 1$ mutant in the $\sum 1278 \mathrm{~b}$ strain background. Here, Las $17 \mathrm{p}$ overexpression restored invasive growth of the $\Delta y n o 1$ mutant (Figure $7 \mathrm{C}$ ). 

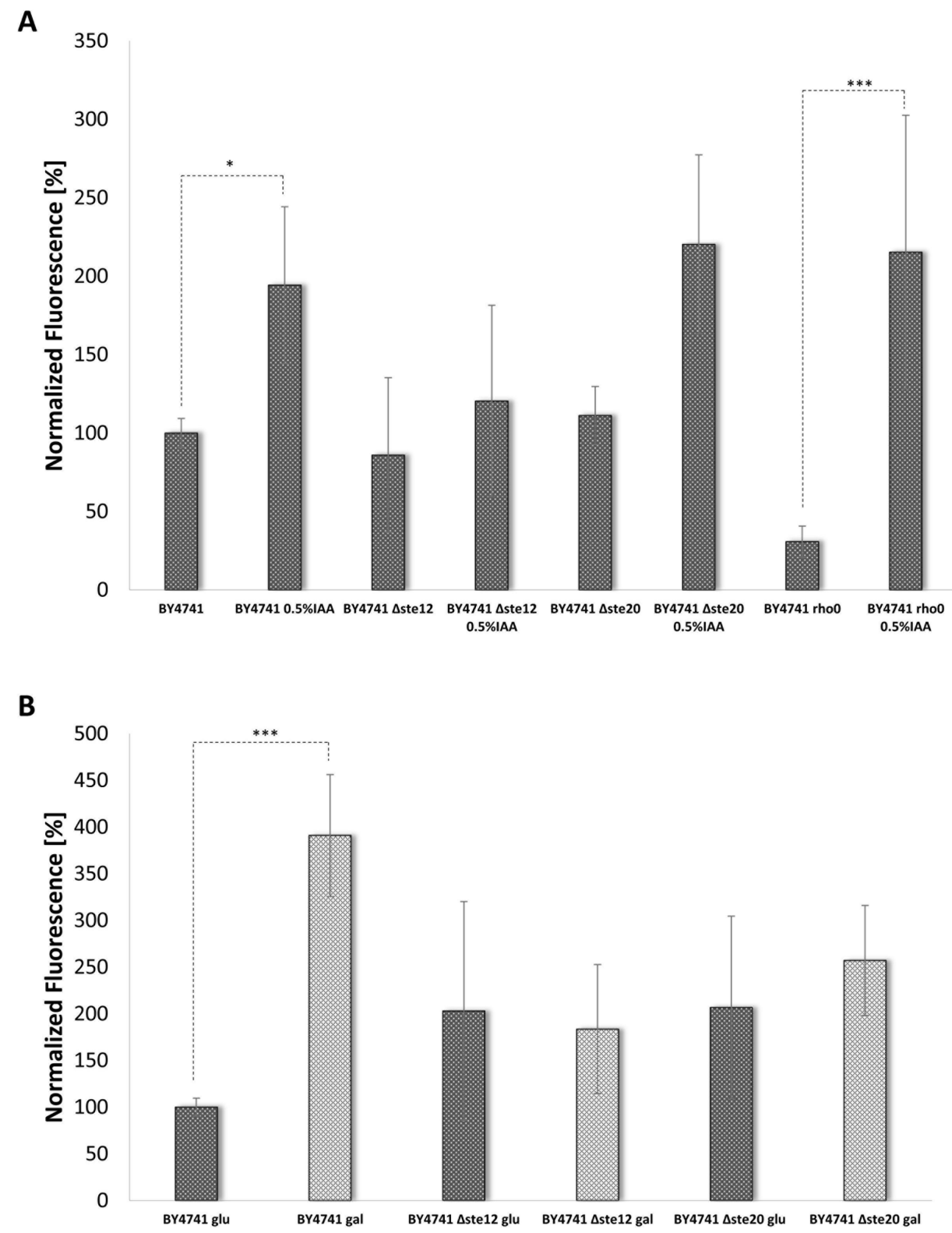

C

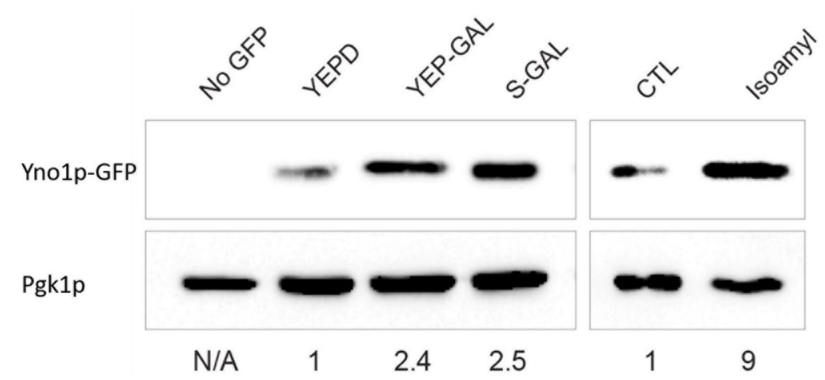

Figure 6. Expression of YNO1 under conditions that stimulate filamentous growth. The expression of YNO1 was analyzed using the GFP-reporter construct in the strains BY4741 rho+, BY4741 rho0, BY4741 $\Delta$ ste20, and BY4741 $\Delta$ ste12. Filamentous growth was induced by addition of $0.5 \%$ isoamyl alcohol (IAA) for $36 \mathrm{~h}(\mathbf{A})$ or growth in galactose media $(\mathbf{B})\left({ }^{*}: p<0.1 ; * * *\right.$ $p<0.01)$. In (C), immunoblot analysis of cells harboring a YNO1-GFP fusion (BY4741 YNO1-GFP::HIS3) were grown under the indicated conditions. A control strain (BY4741) was used for the no-GFP control. Equivalently run blots were probed using antibodies to Pgk1 as a loading control. Band intensity of GFP normalized to Pgk1 levels is shown below the blots and was determined by Bio-Rad XRS ${ }^{+}$Image Lab software. 


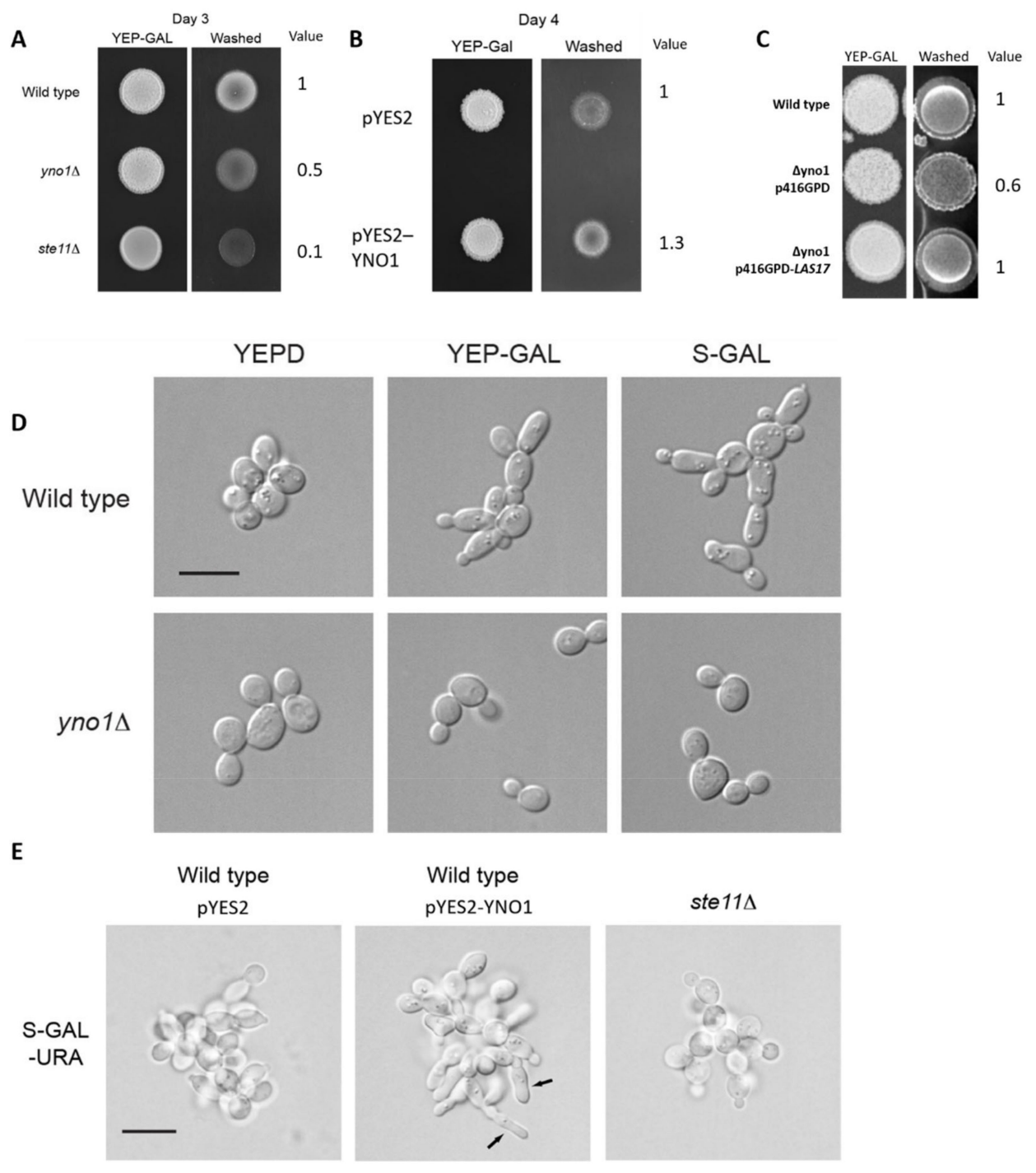

Figure 7. Evaluating the role of Yno1p in regulating filamentous growth. (A) Wild type cells (PC538), the $\Delta y n o 1$ mutant (PC7010), and the $\Delta$ ste11 mutant (PC3861) in the $\sum 1278 \mathrm{~b}$ strain background were spotted onto YEP-GAL media for 3 days at $30{ }^{\circ} \mathrm{C}$. The plate was photographed, washed in a stream of water, and photographed again. (B) Wild type $\Sigma 1278 \mathrm{~b}$ cells (PC538) harboring PYES2 or pYES2-YNO1 plasmids were grown on SC-Ura to maintain selection for the plasmids and spotted onto YEP-GAL media and incubated for 4 days at $30^{\circ} \mathrm{C}$. The plate was photographed, washed in a stream of water and photographed again. (C) Wild type cells and the $\triangle y$ no1 mutant either harboring p416GPD or p416GPD-LAS17 plasmids after selection on SC-Ura were spotted onto YEP-GAL media incubated for 4 days at $30^{\circ} \mathrm{C}$. The plate wash assays (PWA) in (A-C) was repeated in multiple biological replicates and invasive growth was quantified using ImageJ. In (A), wild type invasion was set to a value of 1.0 , which varied by \pm 0.05 across trials. The invasive growth of the $\Delta y n o 1$ mutant was $0.55 \pm$ 0.11 , and $\Delta$ ste 11 was $0.1 \pm 0.09(\mathrm{~N}=3, p<0.03)$. In $(\mathbf{B})$, wild type invasion was set to a value of 1.0 , which varied by \pm 0.12 across trials. The invasion of pYES-YNO1 was $1.42 \pm 0.14(\mathrm{~N}=3, p<0.01)$. In $(\mathrm{C})$, the intensity of the spots after the PWA are indistinguishable between the wild type p416GPD and $\triangle y$ no1 p416GPD-LAS17 cells and are reduced to $0.8+/-0.1$ in the $\triangle y$ no1 $p 416 G P D$ mutant $(\mathrm{N}=4 ; p=0 . p=0.05)$. (D) Wild type cells (PC538) and the $\Delta y n o 1$ mutant (PC7010) were grown to mid-log phase in YEPD, YEP-GAL, or S-GAL media and examined by differential interference contrast (DIC) microscopy at 100X magnification. Bar, 10 microns. (E) Analysis of cells overexpressing YNO1 by the single cell invasive growth assay (Cullen and Sprague, 2000). Wild type cells (PC538) cells harboring pYES2 or pYES2-YNO1 were grown to saturation in liquid culture and spread onto SC-Ura medium. A spot of galactose (10 microliters of $20 \%$ galactose) was spotted onto the plate, which was incubated for $16 \mathrm{~h}$ at $30^{\circ} \mathrm{C}$. Cells were examined by DIC microscopy on plates at 100X. Bar, $10 \mathrm{microns}$. Arrows mark several examples of hyper-polarized cells. 
Previously, we have shown that the $\Delta y n o 1$ mutant has less stable F-actin cables. Addition of hydrogen peroxide promotes actin nucleation and can compensate for the loss of Yno1p [5]. We found that low doses of hydrogen peroxide $\left(0.08 \mathrm{mM} \mathrm{H}_{2} \mathrm{O}_{2}\right)$ improved the invasive growth of the $\Delta y n o 1$ strain (Figure 8). This result supports the idea that reduced superoxide/hydrogen peroxide underlies the invasive growth defect of the $\Delta y n o 1$ mutant. Higher doses of hydrogen peroxide $\left(0.8 \mathrm{mM} \mathrm{H}_{2} \mathrm{O}_{2}\right)$ further improved invasive growth. In a $\Delta$ ste11 mutant, addition of hydrogen peroxide had no effect. Therefore, Ynolp-dependent control of ROS is a component of the filamentous growth response in yeast.

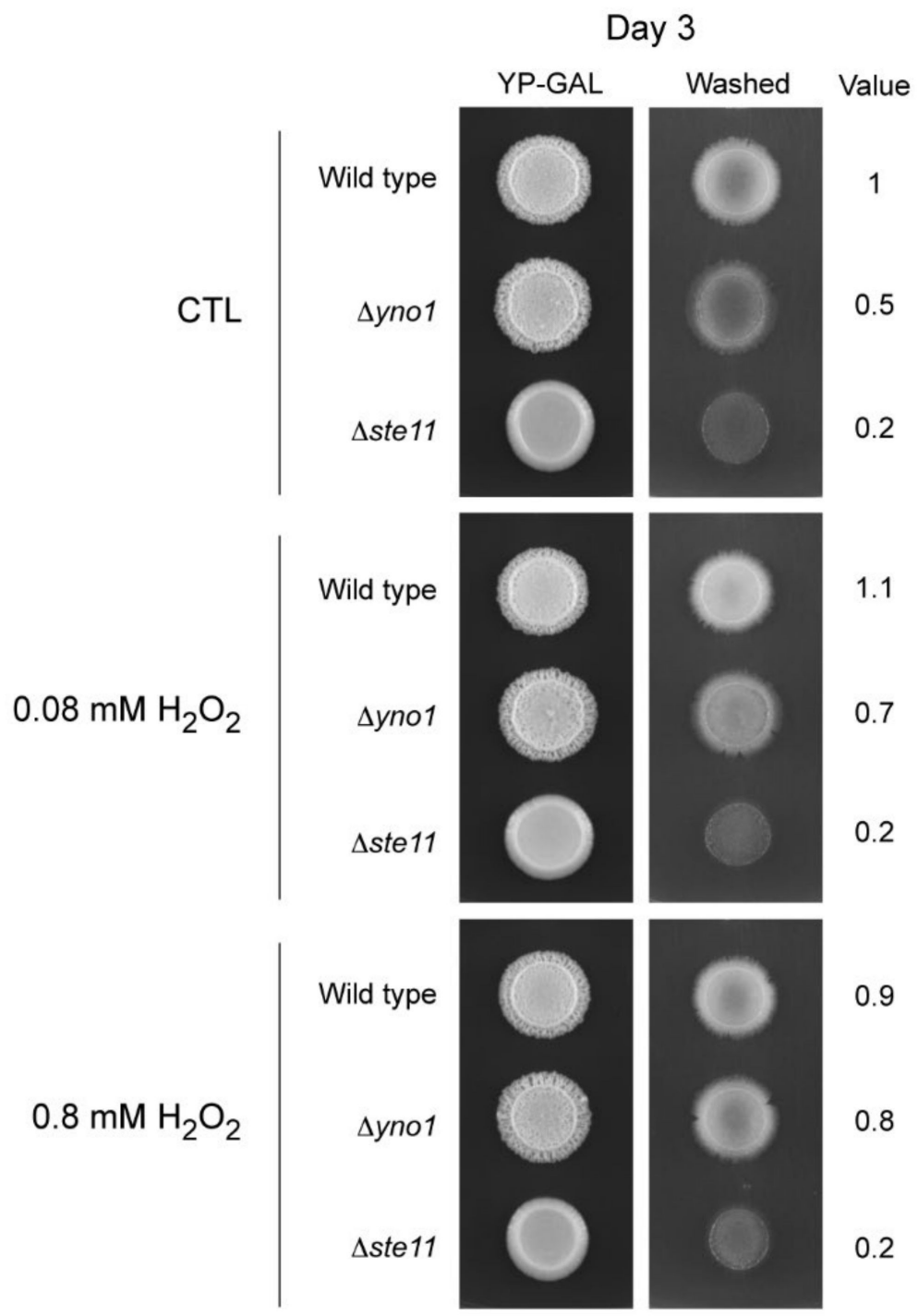

Figure 8. The effect of hydrogen peroxide on invasive growth of the $\Delta y n o 1$ mutant alongside control strains. Wild type cells (PC538), the $\Delta y n o 1$ mutant (PC7010) and the $\Delta$ ste11 mutant (PC3861) in the $\sum 1278 \mathrm{~b}$ strain background were spotted onto YEP-GAL media containing the indicated concentrations of $\mathrm{H}_{2} \mathrm{O}_{2}$ for 3 days at $30^{\circ} \mathrm{C}$. Plates were photographed, washed, and photographed again. Invasive growth was quantified by ImageJ analysis.

\subsection{Yno1p, Actin Polymerization and Filamentous Growth}

We also tested the effect of Yno1p on the F-actin system during filamentous growth using a collection of rho0 $\Sigma 1278$ b strains expressing Abp140mRFP from chromosomal sites. To obtain exponentially growing cells for investigation, we grew the strains in glucose-containing synthetic media (SC-Ura) to which $20 \%$ galactose was added (up to $3 \%$ ). Galactose induced not only the invasive growth in wild type rho0 strains, but also led to 
an overproduction of Yno1p in a particular strain harboring an extra copy of YNO1 on the vector pYES2. Since the F-actin system is highly dynamic, we analyzed the rearrangement of Abp140mRFP in corresponding strains at a single cortical layer in time (Figure 9).

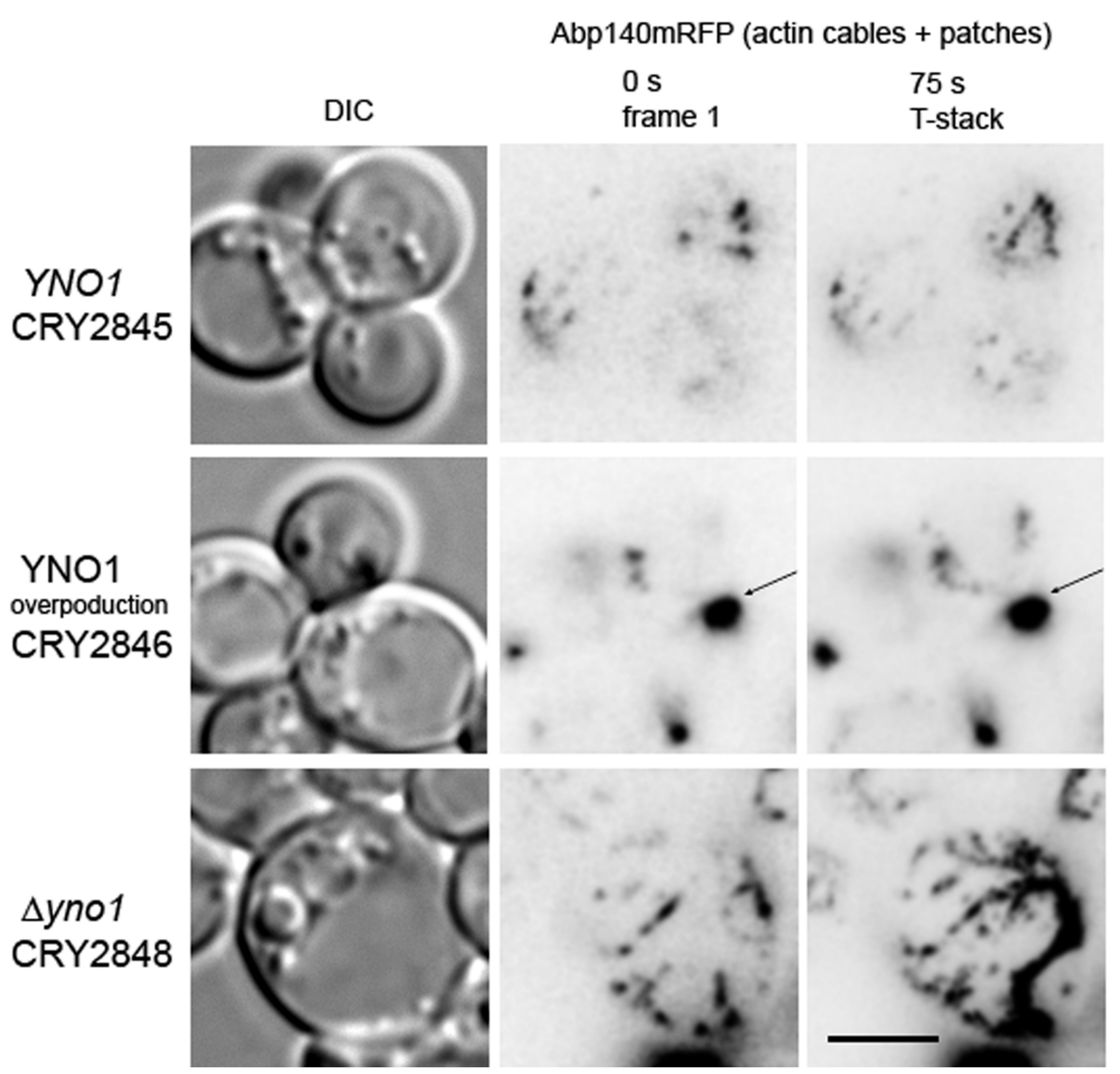

Figure 9. The effect of Yno1p on F-actin distribution at the cell cortex. F-actin structures were visualized by expression from an Abp140-mRFP fusion protein that is integrated into the chromosome. The strains CRY 2845 (MATa SY3089 ste4 FUS1-lacZ FUS1-HIS3 ura3-52; pYES ABP140-RFP-T rho0), CRY 2846 (MATa SY3089 ste4 FUS1-lacZ FUS1-HIS3 ura3-52; pYES YNO1 ABP140-RFP-T rho0), and CRY 2848 (MATa SY3089 ste4 FUS1-lacZ FUS1-HIS3 ura3-52; yno1::KIURA3 ABP140-RFP-T rho-) were grown in synthetic SC-Ura medium and analyzed after addition of $3 \%$ galactose for $7 \mathrm{~h}$. Dynamics of F-actin structures was expressed as a T-stack (superposition of 15 images of the cortical F-actin taken in 5 sec intervals). For each strain at least 3 biological and more than 100 cells were inspected. In the strain CRY2845 small actin patches were observed, whereas in the strain CRY2848 there was a prevalence for cortical actin cables. In strain CRY2846, static F-actin bodies of large size are frequently formed (arrow). Bar, $5 \mu \mathrm{m}$.

We found that wild type cells display a dynamic system of actin patches and filaments. Similar to WT cells, the $\Delta y n o 1$ cells did not display a loss of cortical actin cables. These cells were usually enlarged, and their enlargement was associated with an increased number of cortical actin cables, and their increased dynamics. The enlarged and round morphology 
of the $\Delta y n o 1$ mutant might account for its invasive growth defect. In contrast, the overproduction of Yno1 in this genetic background cells led to a subsequent accumulation of F-actin packages moving along the cortical actin filaments (see Supplementary Movies). Our experiments suggest that the localized activity of Yno1p is required for stabilization of cortical bulk of actin, which would be expected to promote the increase in cell polarization that occurs during filamentous growth.

\section{Discussion}

A longstanding and popular paradigm has been that ROS are detrimental for the cell. In 1956, Denham Harman proposed his famous "Free Radical of Aging Theory" [80]. In this pioneering publication, it was proposed that irradiation of cells resulted in the emergence of ROS thus leading to cellular damage, DNA mutations, cancer, and finally aging. By the turn of the century, this theory was challenged by several key discoveries. Mitohormesis describes a phenomenon in which impaired glycolysis leads to a stimulation of mitochondrial respiration attributed with an increased ROS production. Surprisingly, this surplus of ROS resulted in the increase of lifespan in the model worm C. elegans [81]. The "aging-ROS" contradiction is the focus of a well-written review [82]. It is now becoming increasingly clear that ROS, although detrimental in some settings, can also act as important signaling molecules.

In fungi, both ROS and NADPH oxidases fulfill important signaling functions that mainly contribute to cellular differentiation. ROS generation is connected to filamentous growth by several different mechanisms [83-85], although the mechanisms by which ROS generation is regulated remains incompletely explored. In filamentous fungi, such as Aspergillus nidulans, Podospora anserina, and Neurospora crassa, NADPH oxidases and, thus, ROS are involved in the development of fruiting bodies (cleistothecia) [86-89]. In the grass endosymbiont Epichloe festucae, NADPH oxidases are needed for asexual spore formation and polarized growth including the formation of hyphae [90]. The NADPH oxidase NoxA functions in a complex with the NOX regulator NoxR. NoxR fulfills the function of a scaffold that establishes contact to BemA and Cdc24 (a GEF for Cdc42) that are essential for polarized growth [90].

These observations are consistent with our findings in S. cerevisiae. It was previously demonstrated that the yeast NADPH oxidase Yno1p is involved in both the stabilization of Yck1/2p and localization of Ras2p [8,15]. In some settings, Ras2p has been shown to regulate the small (monomeric) Rho-like GTPase Cdc42, which is a "master regulator" of polarized growth [31]. Deduced from several synthetic lethality screens and loss-offunction studies a genetic interaction between Bem2p/Cdc42p and Yck1/2p can also be speculated [91-93]. In fact, we observed a genetic interaction between Bem2p (one of the GAPs for Cdc42p [94]) and Yno1p. The $\Delta b e m 2 \Delta y n o 1$ double mutant was hypersensitive to wiskostatin, an F-actin inhibitor. In general, most phenotypes of Ynolp are deeply interwoven with the nucleation of actin. Cdc42p mediates actin polymerization via a complex interplay between the Las17p/Vrp1p dimer, and the Arp2/3 complex [95].

Deletion of $Y N O 1$ increased the sensitivity to wiskostatin in a $\Delta v r p 1$ or $\Delta$ las17 background. This result indicates that Yno1p activity and Las17p/Vrp1 probably act in parallel pathways during regulation of the actin cytoskeleton. However, we could also observe that a double deletion of LAS17 and VRP1 is synthetic lethal.

During osmotic stress, the actin cytoskeleton is also reorganized [40]. We show that addition of $1 \mathrm{M} \mathrm{NaCl}$ induced the transcription of the YNO1 gene, which was dependent on the transcription factor Msn2p. Vacuolar fragmentation, which occurs in response to osmotic shock and is dependent on actin polymerization [42,96], was more severe and lasted for a longer time in the $\Delta y n o 1$ mutant. During osmotic stress, Yno1p interacts with Sod1p to produce hydrogen peroxide. A $\Delta y n o 1 \Delta$ sod1 double mutant shows an increased wiskostatin sensitivity compared to the respective single gene deletions. Recently, it was demonstrated that vacuoles in a $\Delta s o d 1$ background show elevated vacuolar fragmentation [97]. Experiments in the plant Arabidopsis thaliana demonstrate that the importance of ROS as second 
messengers in response to hyperosmotic shock are evolutionary conserved [98]. Our data also indicate that Yno1p via the activation of Cdc42p regulates its own transcription, actin polymerization and osmotic stress response in parallel. Such a feed forward situation leads to an increase in Yno1p activity and the resulting burst of ROS would lead to cellular damage. Such a system could work well if there is also a mechanism of deactivation after the adaptation phase. This particular positive feedback loop is eventually stopped by the ERAD as previously demonstrated for Yno1p [15]. Eventually also catalases are involved in the removal of a $\mathrm{H}_{2} \mathrm{O}_{2}$ excess and thus "over signaling".

The actin cytoskeleton is also reorganized during morphogenetic responses that are controlled by signal transduction pathways. One example is filamentous/invasive growth, which is controlled by many pathways, including a Cdc42p-dependent MAPK pathway, and which involves reorganization of the actin cytoskeleton (Figure 10) [20]. Fusel alcohols and non-preferred carbon sources that induce invasive growth [27] were also found to induce expression of YNO1. Interestingly, deletion of one of the transcription factors that regulates the fMAPK pathway, STE12, reduced the transcriptional induction of YNO1 to galactose, but not to IAA (Figure 10). Therefore, the expression of YNO1 might be induced by multiple triggers of filamentous/invasive growth.

Yno1p was required for invasive growth, which might result from hydrogen peroxide production, which leads to altered actin filament assembly. Addition of $\mathrm{H}_{2} \mathrm{O}_{2}$ improved invasive growth in cells lacking Yno1p. Moreover, overexpression of Las17p complemented the invasive growth defect seen in cells lacking Yno1p (Figure 10). Time-lapse microscopy of Abp140mRFP-labeled cells revealed that overexpression of Yno1p induced formation of F-actin bodies in a similar way as described previously by increased concentration of added $\mathrm{H}_{2} \mathrm{O}_{2}$ [99]. These stabile actin aggregates resemble oxidized actin bodies, which may contain various actin-binding proteins. The question remains how the formation of these F-actin structures is related to invasive growth of this particular strain. A role for NADPH oxidases in the regulation of filamentous growth may be conserved among fungi. The NADPH oxidase FRE8 in C. albicans leads to a burst of ROS that is a prerequisite for morphological changes during invasive growth and pathogenicity [6]. Although the closest homologue to Fre8p in C. albicans is not Yno1p but Fre3p in S. cerevisiae, an overexpression of Fre3p in S. cerevisiae did not cause superoxide production, at least under the conditions tested [5]. These findings show that exploring this family of proteins will have value in understanding the role of ROS in fungal dimorphism.

Actin reorganization also occurs during mating projection formation, which is also controlled by a related Cdc42p-dependent MAP kinase pathway. Treatment of Mata cells with alpha factor at levels above physiological concentrations induce apoptotic cell death attributed with a burst of ROS [34]. This could be a trigger to remove cells after unsuccessful mating from the population [100]. In the present work, we show that the ROS is derived from the yeast NADPH oxidase. In the control strain, a 3-fold increase in superoxide levels was detected, whereas in a $\Delta y n o 1$ strain no such increase was observed. It is assumed that low levels of ROS promote cell survival, whereas high doses of ROS initiate apoptosis $[34,101]$. Previously, we showed that overexpression of Yno1p resulted in a 9-fold increase in cellular superoxide levels. These high ROS levels correlate with an increased apoptosis and necrosis. Deletion of the yeast metacaspase Yca1p that is an essential component of the yeast apoptotic program diminished the increased cell death that was induced by YNO1 overexpression. This result demonstrates that ROS per se are not detrimental for the cells, but rather fulfill signaling functions depending on location and concentration of ROS. Although the increase of ROS in the $\triangle y$ no 1 background after addition of alpha factor was not observed, the incidence of apoptosis was still high. In the control strain as well as $\Delta y n o 1$ strain an unphysiological surplus of alpha factor reduced cell survival to less than $50 \%$. This result indicates that ROS originating from the yeast NADPH oxidase Yno1p fulfills signaling functions independent on the induction of apoptosis and polarized growth/shmooing. 


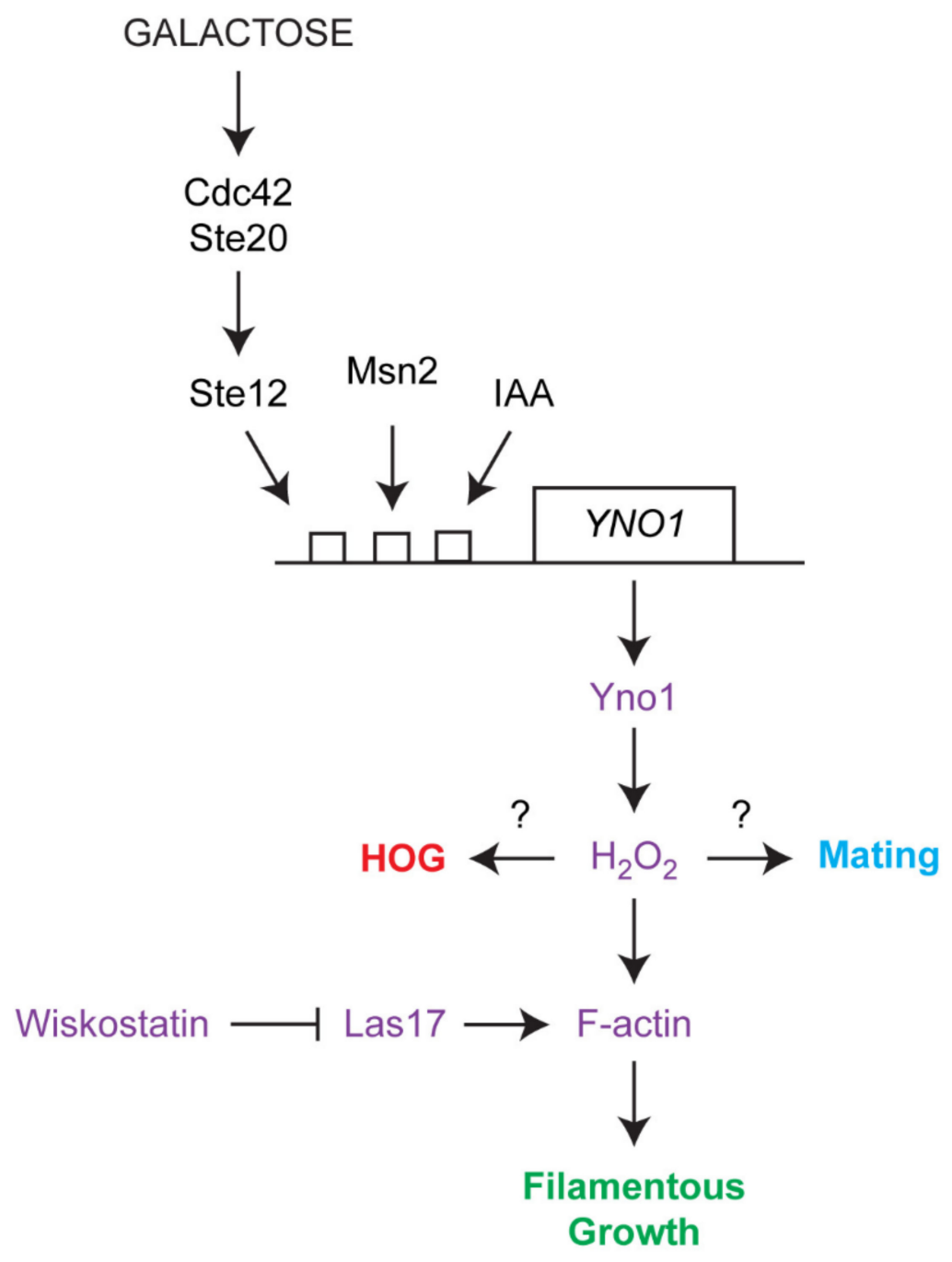

Figure 10. Model for the action Yno1p during filamentous growth. Galactose induces filamentous growth. The transcription factors Ste12p and Msn2p are activated via Cdc42p/Ste20p and promotes the expression of the Yno1p gene. IAA treatment induces filamentous growth and YNO1 expression independent of Ste12p. Yno1p in an interplay with Sod1p produces hydrogen peroxide that is involved in pheromone response (blue letters), osmotic stress response (red letters) and filamentous growth (green letters). An additional target of Yno1p-derived ROS is the actin assembly factor Las17p that promotes the nucleation of F-actin (purple letters). Our data indicate that stabilized F-actin may impact filamentous/invasive growth.

\section{Conclusions}

Branched actin filaments form at sites of polarized growth and their nucleation is dependent on Las17p/Vrp1p as well as the Arp2/3 complex. In yeast cells, the morphological manifestations of this branched F-actins are so called "actin patches" that have to be clearly distinguished from actin cables. In growing cells, these actin patches mark the site of bud emergence and appear afterwards in the daughter cell [102]. Under specific conditions, actin patches also accumulate at the shmoo tip of mating cells and at the distal tip of pseudohyphal cells and are required for the morphological changes of these cells $[20,33]$. By comparison, during osmotic stress actin cables are lost and patches redistribute from the daughter to mother cells [103]. A correct localization of these patches at sites of polar growth and in the cortical regions of the cell is mediated by the plasma membrane bound G-protein Cdc42p by a recruitment of Las17p/Vrp1 and Arp2/3 [104]. In the current work, we show that a yeast NADPH oxidase (Yno1p) is involved in this process. Ynolp produces superoxide that is instantly dismutated into hydrogen peroxide by the superoxide dismu- 
tase Sod1p [8]. This ROS acts as a signaling molecule and seems to modulate actin functions through Las17p as shown by screens based on the drug wiskostatin, a chemical inhibitor of F-actin polymerization. Accordingly, we could demonstrate that Ynolp overexpression leads to larger large actin patches, whereas in the corresponding deletion background the prevalence for actin cables during filamentous growth is increased. Besides its role in actin nucleation, Cdc42p is a central regulator located upstream of several MAPK pathways that modulate the response during filamentous growth, osmotic stress and mating (Figure 1). In a $\triangle y n o 1$ deletion strain, reduced ROS levels occur, which presumably underlie the defects in filamentous growth and recovery of vacuolar morphology upon a hyperosmotic stress. The complexity of this regulatory network is further evident by the fact that transcription factors that are controlled by these MAPK pathways stimulate the expression of the YNO1 gene. Further studies in the emerging field of ROS signaling in Saccharomyces cerevisiae may continue to provide information about this type of signaling response.

Supplementary Materials: The following are available online at https:/ /www.mdpi.com/2076-392 1/10/2/322/s1, Figure S1: GFP-based YNO1-reporter; Supplementary Material (Strains (including construction of the GFP-based YNO1-GFP reporter); media composition; and primer sequences); Supplementary movies (CRY2845; CRY2846; CRY2848).

Author Contributions: M.R., P.J.C. and M.B. concepted the manuscript. M.W., J.H., M.B., C.W.G, P.J.C. and M.R. designed individual experiments. M.W., S.B., B.G., G.P.G., S.S., D.H., J.H. and M.B. performed the experiments. M.W., J.H., M.B., C.W.G, P.J.C. and M.R. analysed data. M.R., P.J.C. and M.W. wrote the manuscript. All authors have read and agreed to the published version of the manuscript.

Funding: The work presented here was supported by grant P33511 of the Austrian Science Fund FWF (to M.R.), P26713 of the FWF to M.B., and NIH grant for P.J.C. (GM098629).

Institutional Review Board Statement: Not applicable.

Informed Consent Statement: Not applicable.

Data Availability Statement: Data is contained within the article or supplementary material.

Acknowledgments: Thanks to M. Whiteway (McGill University) for the plasmids. Thanks to the laboratory members for the suggestions. Open Access Funding by the Austrian Science Fund (FWF).

Conflicts of Interest: The authors declare no conflict of interest.

\begin{abstract}
Abbreviations
ER: endoplasmic reticulum; HOG: hyperosmolarity glycerol response; IAA: isoamyl alcohol; PAK: serine/threonine $\mathrm{p} 21$ activated kinase; MAP: mitogen-activated protein; MAPK: mitogen-activated protein kinase; MAPKK: mitogen-activated protein kinase kinase; MAPKKK: mitogen-activated protein kinase kinase kinase; ROS: reactive oxygen species; DIC: Differential interference contrast; NADPH: Nicotinamide adenine dinucleotide; DHE, dihydroethidium; YEPD: yeast extract peptone dextrose; SDS: sodium-dodecyl-sulfate (SDS); PAGE: polyacrylamide gel electrophoresis: PWA: Plate wash assays.
\end{abstract}

\title{
References
}

1. Breitenbach, M.; Rinnerthaler, M.; Weber, M.; Breitenbach-Koller, H.; Karl, T.; Cullen, P.; Basu, S.; Haskova, D.; Hasek, J. The defense and signaling role of NADPH oxidases in eukaryotic cells: Review. Wien. Med. Wochenschr. 2018, 168, 286-299. [CrossRef]

2. Royer-Pokora, B.; Kunkel, L.M.; Monaco, A.P.; Goff, S.C.; Newburger, P.E.; Baehner, R.L.; Cole, F.S.; Curnutte, J.T.; Orkin, S.H. Cloning the gene for an inherited human disorder-Chronic granulomatous disease-On the basis of its chromosomal location. Nature 1986, 322, 32-38. [CrossRef]

3. Thomas, D.C. The phagocyte respiratory burst: Historical perspectives and recent advances. Immunol. Lett. 2017, 192, 88-96. [CrossRef] [PubMed]

4. Babior, B.M.; Kipnes, R.S.; Curnutte, J.T. Biological Defense Mechanisms the production by leukocytes of superoxide, a potential bactericidal agent. J. Immunol. 2014, 193, 5359-5362. [CrossRef] [PubMed] 
5. Rinnerthaler, M.; Buttner, S.; Laun, P.; Heeren, G.; Felder, T.K.; Klinger, H.; Weinberger, M.; Stolze, K.; Grousl, T.; Hasek, J.; et al. Yno1p/Aim14p, a NADPH-oxidase ortholog, controls extramitochondrial reactive oxygen species generation, apoptosis, and actin cable formation in yeast. Proc. Natl. Acad. Sci. USA 2012, 109, 8658-8663. [CrossRef]

6. Rossi, D.C.P.; Gleason, J.E.; Sanchez, H.; Schatzman, S.S.; Culbertson, E.M.; Johnson, C.J.; McNees, C.A.; Coelho, C.; Nett, J.E.; Andes, D.R.; et al. Candida albicans FRE8 encodes a member of the NADPH oxidase family that produces a burst of ROS during fungal morphogenesis. PLoS Pathog. 2017, 13. [CrossRef]

7. Hajjar, C.; Cherrier, M.V.; Mirandela, G.D.; Petit-Hartlein, I.; Stasia, M.J.; Fontecilla-Camps, J.C.; Fieschi, F.; Dupuy, J. The NOX Family of Proteins Is Also Present in Bacteria. MBio 2017, 8. [CrossRef] [PubMed]

8. Reddi, A.R.; Culotta, V.C. SOD1 integrates signals from oxygen and glucose to repress respiration. Cell 2013, 152, 224-235. [CrossRef]

9. Roth, A.F.; Papanayotou, I.; Davis, N.G. The yeast kinase Yck2 has a tripartite palmitoylation signal. Mol. Biol. Cell 2011, 22, 2702-2715. [CrossRef]

10. Babu, P.; Bryan, J.D.; Panek, H.R.; Jordan, S.L.; Forbrich, B.M.; Kelley, S.C.; Colvin, R.T.; Robinson, L.C. Plasma membrane localization of the Yck2p yeast casein kinase 1 isoform requires the C-terminal extension and secretory pathway function. J. Cell Sci. 2002, 115, 4957-4968. [CrossRef]

11. Snowdon, C.; Johnston, M. A novel role for yeast casein kinases in glucose sensing and signaling. Mol. Biol. Cell 2016, 27, 3369-3375. [CrossRef]

12. Alvaro, C.G.; O’Donnell, A.F.; Prosser, D.C.; Augustine, A.A.; Goldman, A.; Brodsky, J.L.; Cyert, M.S.; Wendland, B.; Thorner, J. Specific alpha-arrestins negatively regulate Saccharomyces cerevisiae pheromone response by down-modulating the G-proteincoupled receptor Ste2. Mol. Cell Biol. 2014, 34, 2660-2681. [CrossRef] [PubMed]

13. Bartels, D.J.; Mitchell, D.A.; Dong, X.W.; Deschenes, R.J. Erf2, a novel gene product that affects the localization and palmitoylation of Ras2 in Saccharomyces cerevisiae. Mol. Cell Biol. 1999, 19, 6775-6787. [CrossRef] [PubMed]

14. Kim, J.H.; Johnston, M. Two glucose-sensing pathways converge on Rgt1 to regulate expression of glucose transporter genes in Saccharomyces cerevisiae. J. Biol Chem. 2006, 281, 26144-26149. [CrossRef]

15. Leadsham, J.E.; Sanders, G.; Giannaki, S.; Bastow, E.L.; Hutton, R.; Naeimi, W.R.; Breitenbach, M.; Gourlay, C.W. Loss of Cytochrome c Oxidase Promotes RAS-Dependent ROS Production from the ER Resident NADPH Oxidase, Yno1p, in Yeast. Cell Metab. 2013, 18, 279-286. [CrossRef]

16. Gale, C.A.; Bendel, C.M.; McClellan, M.; Hauser, M.; Becker, J.M.; Berman, J.; Hostetter, M.K. Linkage of adhesion, filamentous growth, and virulence in Candida albicans to a single gene, INT1. Science 1998, 279, 1355-1358. [CrossRef]

17. Whiteway, M.; Bachewich, C. Morphogenesis in Candida albicans. Annu. Rev. Microbiol. 2007, 61, 529-553. [CrossRef]

18. Gimeno, C.J.; Ljungdahl, P.O.; Styles, C.A.; Fink, G.R. Unipolar Cell Divisions in the Yeast Saccharomyces-Cerevisiae Lead to Filamentous Growth-Regulation by Starvation and Ras. Cell 1992, 68, 1077-1090. [CrossRef]

19. Kron, S.J.; Styles, C.A.; Fink, G.R. Symmetric cell division in pseudohyphae of the yeast Saccharomyces cerevisiae. Mol. Biol. Cell 1994, 5, 1003-1022. [CrossRef]

20. Cali, B.M.; Doyle, T.C.; Botstein, D.; Fink, G.R. Multiple functions for actin during filamentous growth of Saccharomyces cerevisiae. Mol. Biol. Cell 1998, 9, 1873-1889. [CrossRef] [PubMed]

21. Taheri, N.; Kohler, T.; Braus, G.H.; Mosch, H.U. Asymmetrically localized Bud8p and Bud9p proteins control yeast cell polarity and development. EMBO J. 2000, 19, 6686-6696. [CrossRef] [PubMed]

22. Roberts, R.L.; Fink, G.R. Elements of a single MAP kinase cascade in Saccharomyces cerevisiae mediate two developmental programs in the same cell type: Mating and invasive growth. Genes Dev. 1994, 8, 2974-2985. [CrossRef]

23. Robertson, L.S.; Fink, G.R. The three yeast A kinases have specific signaling functions in pseudohyphal growth. Proc. Natl. Acad. Sci. USA 1998, 95, 13783-13787. [CrossRef]

24. Lorenz, M.C.; Heitman, J. Yeast pseudohyphal growth is regulated by GPA2, a G protein alpha homolog. EMBO J. 1997, 16, 7008-7018. [CrossRef]

25. Pan, X.; Heitman, J. Cyclic AMP-dependent protein kinase regulates pseudohyphal differentiation in Saccharomyces cerevisiae. Mol. Cell Biol. 1999, 19, 4874-4887. [CrossRef] [PubMed]

26. Lamb, T.M.; Mitchell, A.P. The transcription factor Rim101p governs ion tolerance and cell differentiation by direct repression of the regulatory genes NRG1 and SMP1 in Saccharomyces cerevisiae. Mol. Cell Biol. 2003, 23, 677-686. [CrossRef] [PubMed]

27. Cullen, P.J.; Sprague, G.F. The Regulation of Filamentous Growth in Yeast. Genetics 2012, 190, 23-49. [CrossRef]

28. Cullen, P.J.; Sabbagh, W.; Graham, E.; Irick, M.M.; van Olden, E.K.; Neal, C.; Delrow, J.; Bardwell, L.; Sprague, G.F. A signaling mucin at the head of the Cdc42- and MAPK-dependent filamentous growth pathway in yeast. Gene Dev. 2004, 18, 1695-1708. [CrossRef]

29. Peter, M.; Neiman, A.M.; Park, H.O.; vanLohuizen, M.; Herskowitz, I. Functional analysis of the interaction between the small GTP binding protein Cdc42 and the Ste20 protein kinase in yeast. EMBO J. 1996, 15, 7046-7059. [CrossRef]

30. Gancedo, J.M. Control of pseudohyphae formation in Saccharomyces cerevisiae. FEMS Microbiol. Rev. 2001, 25, 107-123. [CrossRef]

31. Mosch, H.U.; Roberts, R.L.; Fink, G.R. Ras2 signals via the Cdc42/Ste20/mitogen-activated protein kinase module to induce filamentous growth in Saccharomyces cerevisiae. Proc. Natl. Acad. Sci. USA 1996, 93, 5352-5356. [CrossRef] 
32. Chen, R.E.; Thorner, J. Function and regulation in MAPK signaling pathways: Lessons learned from the yeast Saccharomyces cerevisiae. Biochim. Biophys. Acta 2007, 1773, 1311-1340. [CrossRef]

33. Smith, M.G.; Swamy, S.R.; Pon, L.A. The life cycle of actin patches in mating yeast. J. Cell Sci. 2001, 114, 1505-1513. [PubMed]

34. Severin, F.F.; Hyman, A.A. Pheromone induces programmed cell death in S. cerevisiae. Curr. Biol. 2002, 12, R233-235. [CrossRef]

35. Saito, H. Regulation of cross-talk in yeast MAPK signaling pathways. Curr. Opin. Microbiol. 2010, 13, 677-683. [CrossRef]

36. Nishimura, A.; Yamamoto, K.; Oyama, M.; Kozuka-Hata, H.; Saito, H.; Tatebayashi, K. Scaffold Protein Ahk1, Which Associates with Hkr1, Sho1, Ste11, and Pbs2, Inhibits Cross Talk Signaling from the Hkr1 Osmosensor to the Kss1 Mitogen-Activated Protein Kinase. Mol. Cell Biol. 2016, 36, 1109-1123. [CrossRef] [PubMed]

37. Pitoniak, A.; Birkaya, B.; Dionne, H.M.; Vadaie, N.; Cullen, P.J. The Signaling Mucins Msb2 and Hkr1 Differentially Regulate the Filamentation Mitogen-activated Protein Kinase Pathway and Contribute to a Multimodal Response. Mol. Biol. Cell 2009, 20, 3101-3114. [CrossRef]

38. Tanaka, K.; Tatebayashi, K.; Nishimura, A.; Yamamoto, K.; Yang, H.Y.; Saito, H. Yeast Osmosensors Hkr1 and Msb2 Activate the Hog1 MAPK Cascade by Different Mechanisms. Sci. Signal. 2014, 7. [CrossRef] [PubMed]

39. Tatebayashi, K.; Tanaka, K.; Yang, H.Y.; Yamamoto, K.; Matsushita, Y.; Tomida, T.; Imai, M.; Saito, H. Transmembrane mucins Hkr1 and Msb2 are putative osmosensors in the SHO1 branch of yeast HOG pathway. EMBO J. 2007, 26, 3521-3533. [CrossRef]

40. Hohmann, S. Osmotic stress signaling and osmoadaptation in Yeasts. Microbiol. Mol. Biol. R. 2002, 66, 300-372. [CrossRef] [PubMed]

41. Monteiro, P.T.; Oliveira, J.; Pais, P.; Antunes, M.; Palma, M.; Cavalheiro, M.; Galocha, M.; Godinho, C.P.; Martins, L.C.; Bourbon, N.; et al. YEASTRACT plus: A portal for cross-species comparative genomics of transcription regulation in yeasts. Nucleic Acids Res. 2020, 48, D642-D649. [CrossRef] [PubMed]

42. Isgandarova, S.; Jones, L.; Forsberg, D.; Loncar, A.; Dawson, J.; Tedrick, K.; Eitzen, G. Stimulation of actin polymerization by vacuoles via Cdc42p-dependent signaling. J. Biol. Chem. 2007, 282, 30466-30475. [CrossRef]

43. Li, S.C.; Kane, P.M. The yeast lysosome-like vacuole: Endpoint and crossroads. BBA-Mol. Cell Res. 2009, 1793, 650-663. [CrossRef] [PubMed]

44. Brachmann, C.B.; Davies, A.; Cost, G.J.; Caputo, E.; Li, J.C.; Hieter, P.; Boeke, J.D. Designer deletion strains derived from Saccharomyces cerevisiae S288C: A useful set of strains and plasmids for PCR-mediated gene disruption and other applications. Yeast 1998, 14, 115-132. [CrossRef]

45. Van Dyk, D.; Pretorius, I.S.; Bauer, F.F. Mss11p is a central element of the regulatory network that controls FLO11 expression and invasive growth in Saccharomyces cerevisiae. Genetics 2005, 169, 91-106. [CrossRef] [PubMed]

46. Klinger, H.; Rinnerthaler, M.; Lam, Y.T.; Laun, P.; Heeren, G.; Klocker, A.; Simon-Nobbe, B.; Dickinson, J.R.; Dawes, I.W.; Breitenbach, M. Quantitation of (a)symmetric inheritance of functional and of oxidatively damaged mitochondrial aconitase in the cell division of old yeast mother cells. Exp. Gerontol. 2010, 45, 533-542. [CrossRef]

47. Streubel, M.K.; Bischof, J.; Weiss, R.; Duschl, J.; Liedl, W.; Wimmer, H.; Breitenbach, M.; Weber, M.; Geltinger, F.; Richter, K.; et al. Behead and live long or the tale of cathepsin L. Yeast 2018, 35, 237-249. [CrossRef]

48. Cullen, P.J.; Sprague, G.F. Glucose depletion causes haploid invasive growth in yeast. Proc. Natl. Acad. Sci. USA 2000, 97, 13619-13624. [CrossRef]

49. Zupan, J.; Raspor, P. Quantitative agar-invasion assay. J. Microbiol. Methods 2008, 73, 100-104. [CrossRef]

50. Basu, S.; Vadaie, N.; Prabhakar, A.; Li, B.; Adhikari, H.; Pitoniak, A.; Chow, J.; Chavel, C.A.; Cullen, P.J. Spatial landmarks regulate a Cdc42-dependent MAPK pathway to control differentiation and the response to positional compromise. Proc. Natl. Acad. Sci. USA 2016, 113, E2019-2028. [CrossRef]

51. Michaillat, L.; Mayer, A. Identification of Genes Affecting Vacuole Membrane Fragmentation in Saccharomyces cerevisiae. PLoS ONE 2013, 8, e54160. [CrossRef]

52. Heeren, G.; Rinnerthaler, M.; Laun, P.; von Seyerl, P.; Kossler, S.; Klinger, H.; Hager, M.; Bogengruber, E.; Jarolim, S.; Simon-Nobbe, B.; et al. The mitochondrial ribosomal protein of the large subunit, Afo1p, determines cellular longevity through mitochondrial back-signaling via TOR1. Aging-Us 2009, 1, 622-636. [CrossRef]

53. Grant, C.M.; MacIver, F.H.; Dawes, I.W. Mitochondrial function is required for resistance to oxidative stress in the yeast Saccharomyces cerevisiae. FEBS Lett. 1997, 410, 219-222. [CrossRef]

54. Pyatrikas, D.V.; Fedoseeva, I.V.; Varakina, N.N.; Rusaleva, T.M.; Stepanov, A.V.; Fedyaeva, A.V.; Borovskii, G.B.; Rikhvanov, E.G. Relation between cell death progression, reactive oxygen species production and mitochondrial membrane potential in fermenting Saccharomyces cerevisiae cells under heat-shockconditions. FEMS Microbiol. Lett. 2015, 362. [CrossRef]

55. Fernandes, D.C.; Wosniak, J., Jr.; Pescatore, L.A.; Bertoline, M.A.; Liberman, M.; Laurindo, F.R.; Santos, C.X. Analysis of DHEderived oxidation products by HPLC in the assessment of superoxide production and NADPH oxidase activity in vascular systems. Am. J. Physiol. Cell Physiol. 2007, 292, C413-422. [CrossRef] [PubMed]

56. Dikalov, S.; Nazarewicz, R.; Panov, A.; Harrison, D.G.; Dikalova, A. Crosstalk Between Mitochondrial ROS and NADPH Oxidases in Cardiovascular and Degenerative Diseases: Application of Mitochondria-Targeted Antioxidants. Free Radic. Bio. Med. 2011, 51, S85-S86. [CrossRef]

57. Zorov, D.B.; Juhaszova, M.; Sollott, S.J. Mitochondrial Reactive Oxygen Species (Ros) and Ros-Induced Ros Release. Physiol. Rev. 2014, 94, 909-950. [CrossRef] 
58. Yi, D.G.; Hong, S.; Huh, W.K. Mitochondrial dysfunction reduces yeast replicative lifespan by elevating RAS-dependent ROS production by the ER-localized NADPH oxidase Yno1. PLoS ONE 2018, 13, e0198619. [CrossRef] [PubMed]

59. Mateus, C.; Avery, S.V. Destabilized green fluorescent protein for monitoring dynamic changes in yeast gene expression with flow cytometry. Yeast 2000, 16, 1313-1323. [CrossRef]

60. Peterson, J.R.; Bickford, L.C.; Morgan, D.; Kim, A.S.; Ouerfelli, O.; Kirschner, M.W.; Rosen, M.K. Chemical inhibition of N-WASP by stabilization of a native autoinhibited conformation. Nat. Struct. Mol. Biol. 2004, 11, 747-755. [CrossRef]

61. Madania, A.; Dumoulin, P.; Grava, S.; Kitamoto, H.; Scharer-Brodbeck, C.; Soulard, A.; Moreau, V.; Winsor, B. The Saccharomyces cerevisiae homologue of human Wiskott-Aldrich syndrome protein Las17p interacts with the Arp2/3 complex. Mol. Biol. Cell 1999, 10, 3521-3538. [CrossRef]

62. Aspenstrom, P. The verprolin family of proteins: Regulators of cell morphogenesis and endocytosis. FEBS Lett. 2005, 579, 5253-5259. [CrossRef]

63. Tyler, J.J.; Allwood, E.G.; Ayscough, K.R. WASP family proteins, more than Arp2/3 activators. Biochem. Soc. Trans. 2016, 44, 1339-1345. [CrossRef] [PubMed]

64. Raitt, D.C.; Posas, F.; Saito, H. Yeast Cdc42 GTPase and Ste20 PAK-like kinase regulate Sho1-dependent activation of the Hog1 MAPK pathway. EMBO J. 2000, 19, 4623-4631. [CrossRef]

65. Leberer, E.; Dignard, D.; Harcus, D.; Thomas, D.Y.; Whiteway, M. The Protein-Kinase Homolog Ste20p Is Required to Link the Yeast Pheromone Response G-Protein Beta-Gamma Subunits to Downstream Signaling Components. EMBO J. 1992, 11, 4815-4824. [CrossRef]

66. Huh, G.H.; Damsz, B.; Matsumoto, T.K.; Reddy, M.P.; Rus, A.M.; Ibeas, J.I.; Narasimhan, M.L.; Bressan, R.A.; Hasegawa, P.M. Salt causes ion disequilibrium-induced programmed cell death in yeast and plants. Plant J. 2002, 29, 649-659. [CrossRef]

67. Wadskog, I.; Maldener, C.; Proksch, A.; Madeo, F.; Adler, L. Yeast lacking the SRO7/SOP1-encoded tumor suppressor homologue show increased susceptibility to apoptosis-like cell death on exposure to NaCl stress. Mol. Biol. Cell 2004, 15, 1436-1444. [CrossRef]

68. Rep, M.; Reiser, V.; Gartner, U.; Thevelein, J.M.; Hohmann, S.; Ammerer, G.; Ruis, H. Osmotic stress-induced gene expression in Saccharomyces cerevisiae requires Msn1p and the novel nuclear factor Hot1p. Mol. Cell Biol. 1999, 19, 5474-5485. [CrossRef] [PubMed]

69. Gorner, W.; Durchschlag, E.; Martinez-Pastor, M.T.; Estruch, F.; Ammerer, G.; Hamilton, B.; Ruis, H.; Schuller, C. Nuclear localization of the $\mathrm{C} 2 \mathrm{H} 2$ zinc finger protein Msn2p is regulated by stress and protein kinase A activity. Gene Dev. 1998, $12,586-597$. [CrossRef]

70. Berry, D.B.; Gasch, A.P. Stress-activated Genomic Expression Changes Serve a Preparative Role for Impending Stress in Yeast. Mol. Biol. Cell 2008, 19, 4580-4587. [CrossRef] [PubMed]

71. Miermont, A.; Waharte, F.; Hu, S.Q.; McClean, M.N.; Bottani, S.; Leon, S.; Hersen, P. Severe osmotic compression triggers a slowdown of intracellular signaling, which can be explained by molecular crowding. Proc. Natl. Acad. Sci. USA 2013, 110, 5725-5730. [CrossRef] [PubMed]

72. Vida, T.A.; Emr, S.D. A New Vital Stain for Visualizing Vacuolar Membrane Dynamics and Endocytosis in Yeast. J. Cell Biol. 1995, 128, 779-792. [CrossRef]

73. Dickinson, J.R. 'Fusel' alcohols induce hyphal-like extensions and pseudohyphal formation in yeasts. Microbiology 1996, 142, 1391-1397. [CrossRef]

74. Lorenz, M.C.; Cutler, N.S.; Heitman, J. Characterization of alcohol-induced filamentous growth in Saccharomyces cerevisiae. Mol. Biol. Cell 2000, 11, 183-199. [CrossRef]

75. Adhikari, H.; Cullen, P.J. Metabolic Respiration Induces AMPK- and Ire1p-Dependent Activation of the p38-Type HOG MAPK Pathway. PLoS Genet. 2014, 10. [CrossRef] [PubMed]

76. Madhani, H.D.; Galitski, T.; Lander, E.S.; Fink, G.R. Effectors of a developmental mitogen-activated protein kinase cascade revealed by expression signatures of signaling mutants. Proc. Natl. Acad. Sci. USA 1999, 96, 12530-12535. [CrossRef] [PubMed]

77. Palecek, S.P.; Parikh, A.S.; Kron, S.J. Genetic analysis reveals that FLO11 upregulation and cell polarization independently regulate invasive growth in Saccharomyces cerevisiae. Genetics 2000, 156, 1005-1023. [PubMed]

78. Purevdorj-Gage, B.; Orr, M.E.; Stoodley, P.; Sheehan, K.B.; Hyman, L.E. The role of FLO11 in Saccharomyces cerevisiae biofilm development in a laboratory based flow-cell system. FEMS Yeast Res. 2007, 7, 372-379. [CrossRef]

79. Cullen, P.J. The plate-washing assay: A simple test for filamentous growth in budding yeast. Cold Spring Harb. Protoc. 2015, 2015, 168-171. [CrossRef] [PubMed]

80. Harman, D. Aging: A theory based on free radical and radiation chemistry. J. Gerontol. 1956, 11, 298-300. [CrossRef]

81. Schulz, T.J.; Zarse, K.; Voigt, A.; Urban, N.; Birringer, M.; Ristow, M. Glucose restriction extends Caenorhabditis elegans life span by inducing mitochondrial respiration and increasing oxidative stress. Cell Metab. 2007, 6, 280-293. [CrossRef]

82. Lapointe, J.; Hekimi, S. When a theory of aging ages badly. Cell Mol. Life Sci. 2010, 67, 1-8. [CrossRef] [PubMed]

83. Xu, N.; Cheng, X.X.; Yu, Q.L.; Qian, K.F.; Ding, X.H.; Liu, R.M.; Zhang, B.; Xing, L.J.; Li, M.C. Aft2, a Novel Transcription Regulator, Is Required for Iron Metabolism, Oxidative Stress, Surface Adhesion and Hyphal Development in Candida albicans. PLoS ONE 2013, 8. [CrossRef] [PubMed]

84. Zhang, Y.; Wang, L.; Liang, S.; Zhang, P.; Kang, R.; Zhang, M.; Wang, M.; Chen, L.; Yuan, H.; Ding, S.; et al. FpDep1, a component of Rpd3L histone deacetylase complex, is important for vegetative development, ROS accumulation, and pathogenesis in Fusarium pseudograminearum. Fungal Genet. Biol. 2020, 135, 103299. [CrossRef] [PubMed] 
85. Basso, V.; Znaidi, S.; Lagage, V.; Cabral, V.; Schoenherr, F.; LeibundGut-Landmann, S.; d'Enfert, C.; Bachellier-Bassi, S. The two-component response regulator Skn7 belongs to a network of transcription factors regulating morphogenesis in Candida albicans and independently limits morphogenesis-induced ROS accumulation. Mol. Microbiol. 2017, 106, 157-182. [CrossRef]

86. Breitenbach, M.; Weber, M.; Rinnerthaler, M.; Karl, T.; Breitenbach-Koller, L. Oxidative Stress in Fungi: Its Function in Signal Transduction, Interaction with Plant Hosts, and Lignocellulose Degradation. Biomolecules 2015, 5, 318-342. [CrossRef]

87. Malagnac, F.; Lalucque, H.; Lepere, G.; Silar, P. Two NADPH oxidase isoforms are required for sexual reproduction and ascospore germination in the filamentous fungus Podospora anserina. Fungal Genet. Biol. 2004, 41, 982-997. [CrossRef]

88. Lara-Ortiz, T.; Riveros-Rosas, H.; Aguirre, J. Reactive oxygen species generated by microbial NADPH oxidase NoxA regulate sexual development in Aspergillus nidulans. Mol. Microbiol. 2003, 50, 1241-1255. [CrossRef] [PubMed]

89. Cano-Dominguez, N.; Alvarez-Delfin, K.; Hansberg, W.; Aguirre, J. NADPH oxidases NOX-1 and NOX-2 require the regulatory subunit NOR-1 to control cell differentiation and growth in Neurospora crassa. Eukaryot. Cell 2008, 7, 1352-1361. [CrossRef] [PubMed]

90. Kayano, Y.; Tanaka, A.; Akano, F.; Scott, B.; Takemoto, D. Differential roles of NADPH oxidases and associated regulators in polarized growth, conidiation and hyphal fusion in the symbiotic fungus Epichloe festucae. Fungal Genet. Biol. 2013, 56, 87-97. [CrossRef] [PubMed]

91. Costanzo, M.; Baryshnikova, A.; Bellay, J.; Kim, Y.; Spear, E.D.; Sevier, C.S.; Ding, H.; Koh, J.L.; Toufighi, K.; Mostafavi, S.; et al. The genetic landscape of a cell. Science 2010, 327, 425-431. [CrossRef]

92. Costanzo, M.; VanderSluis, B.; Koch, E.N.; Baryshnikova, A.; Pons, C.; Tan, G.; Wang, W.; Usaj, M.; Hanchard, J.; Lee, S.D.; et al. A global genetic interaction network maps a wiring diagram of cellular function. Science 2016, 353. [CrossRef]

93. Sharifpoor, S.; van Dyk, D.; Costanzo, M.; Baryshnikova, A.; Friesen, H.; Douglas, A.C.; Youn, J.Y.; VanderSluis, B.; Myers, C.L.; Papp, B.; et al. Functional wiring of the yeast kinome revealed by global analysis of genetic network motifs. Genome Res. 2012, 22, 791-801. [CrossRef] [PubMed]

94. Perez, P.; Rincon, S.A. Rho GTPases: Regulation of cell polarity and growth in yeasts. Biochem. J. 2010, 426, 243-253. [CrossRef]

95. Evangelista, M.; Klebl, B.M.; Tong, A.H.Y.; Webb, B.A.; Leeuw, T.; Leberer, E.; Whiteway, M.; Thomas, D.Y.; Boone, C. A role for myosin-I in actin assembly through interactions with Vrp1p, Bee1p, and the Arp2/3 complex. J. Cell Biol. 2000, 148, 353-362. [CrossRef] [PubMed]

96. Tedrick, K.; Trischuk, T.; Lehner, R.; Eitzen, G. Enhanced membrane fusion in sterol-enriched vacuoles bypasses the Vrp1p requirement. Mol. Biol. Cell 2004, 15, 4609-4621. [CrossRef]

97. Montllor-Albalate, C.; Colin, A.E.; Chandrasekharan, B.; Bolaji, N.; Andersen, J.L.; Outten, F.W.; Reddi, A.R. Extra-mitochondrial $\mathrm{Cu} / \mathrm{Zn}$ superoxide dismutase (Sod1) is dispensable for protection against oxidative stress but mediates peroxide signaling in Saccharomyces cerevisiae. Redox Biol. 2019, 21. [CrossRef]

98. Martiniere, A.; Fiche, J.B.; Smokvarska, M.; Mari, S.; Alcon, C.; Dumont, X.; Hematy, K.; Jaillais, Y.; Nollmann, M.; Maurel, C. Osmotic Stress Activates Two Reactive Oxygen Species Pathways with Distinct Effects on Protein Nanodomains and Diffusion. Plant Physiol. 2019, 179, 1581-1593. [CrossRef] [PubMed]

99. Farah, M.E.; Sirotkin, V.; Haarer, B.; Kakhniashvili, D.; Amberg, D.C. Diverse protective roles of the actin cytoskeleton during oxidative stress. Cytoskeleton 2011, 68, 340-354. [CrossRef] [PubMed]

100. Carmona-Gutierrez, D.; Eisenberg, T.; Buttner, S.; Meisinger, C.; Kroemer, G.; Madeo, F. Apoptosis in yeast: Triggers, pathways, subroutines. Cell Death Differ. 2010, 17, 763-773. [CrossRef] [PubMed]

101. Perrone, G.G.; Tan, S.X.; Dawes, I.W. Reactive oxygen species and yeast apoptosis. Biochim. Biophys. Acta 2008, 1783, 1354-1368. [CrossRef] [PubMed]

102. Karpova, T.S.; McNally, J.G.; Moltz, S.L.; Cooper, J.A. Assembly and function of the actin cytoskeleton of yeast: Relationships between cables and patches. J. Cell Biol. 1998, 142, 1501-1517. [CrossRef] [PubMed]

103. Chowdhury, S.; Smith, K.W.; Gustin, M.C. Osmotic stress and the yeast cytoskeleton: Phenotype-specific suppression of an actin mutation. J. Cell Biol. 1992, 118, 561-571. [CrossRef] [PubMed]

104. Lechler, T.; Jonsdottir, G.A.; Klee, S.K.; Pellman, D.; Li, R. A two-tiered mechanism by which Cdc42 controls the localization and activation of an Arp2/3-activating motor complex in yeast. J. Cell Biol. 2001, 155, 261-270. [CrossRef] [PubMed] 